NBER WORKING PAPER SERIES

\title{
MONETARY POLICY AND ENDOGENOUS FINANCIAL CRISES
}

\author{
Frederic Boissay \\ Fabrice Collard \\ Jordi Galí \\ Cristina Manea \\ Working Paper 29602 \\ http://www.nber.org/papers/w29602 \\ NATIONAL BUREAU OF ECONOMIC RESEARCH \\ 1050 Massachusetts Avenue \\ Cambridge, MA 02138 \\ December 2021
}

The views expressed in this paper are our own and should not be interpreted as reflecting the views of the Bank for International Settlements, the Deutsche Bundesbank, the Eurosystem, or the National Bureau of Economic Research. We thank F. Alvarez, G. Barlevy, C. Borio, F. De Fiore, P. Disyatat, M. Hoffmann, T. Holden, E. Mendoza, B. Mojon, C. Pflueger, L. Svensson, P. Rungcharoentkitkul, H. Uhlig, R. Wouters, E. Zakrakšek as well as seminar and conference participants at the NBER Summer Institute, EEA-ESEM 2021 Congress, Ridge Conference, Danmarks Nationalbank-Bundesbank- Norges Bank Conference, Deutsche Bundesbank, National Bank of Belgium, Bank for International Settlements, Universitat Pompeu Fabra, Trinity College, and European Central Bank for helpful discussions. Galí acknowledges financial support from the European Research Council under the European Union's Horizon 2020 research and innovation program, Advanced Grant (882332-HEMPEF), from the Spanish Ministry of Economy and Competitiveness, through the Severo Ochoa Programme for Centres of Excellence in R\&D (CEX2019-000915-S), and from the Generalitat de Catalunya, through CERCA and SGR Programme (2017-SGR-1393).

At least one co-author has disclosed additional relationships of potential relevance for this research. Further information is available online at http://www.nber.org/papers/w29602.ack

NBER working papers are circulated for discussion and comment purposes. They have not been peer-reviewed or been subject to the review by the NBER Board of Directors that accompanies official NBER publications.

(C) 2021 by Frederic Boissay, Fabrice Collard, Jordi Galí, and Cristina Manea. All rights reserved. Short sections of text, not to exceed two paragraphs, may be quoted without explicit permission provided that full credit, including $\odot$ notice, is given to the source. 
Monetary Policy and Endogenous Financial Crises

Frederic Boissay, Fabrice Collard, Jordi Galí, and Cristina Manea

NBER Working Paper No. 29602

December 2021

JEL No. E32,E44,E52

\section{ABSTRACT}

We study whether a central bank should deviate from its objective of price stability to promote financial stability. We tackle this question within a textbook New Keynesian model augmented with capital accumulation and microfounded endogenous financial crises. We compare several interest rate rules, under which the central bank responds more or less forcefully to inflation and aggregate output. Our main findings are threefold. First, monetary policy affects the probability of a crisis both in the short run (through aggregate demand) and in the medium run (through savings and capital accumulation). Second, a central bank can both reduce the probability of a crisis and increase welfare by departing from strict inflation targeting and responding systematically to fluctuations in output. Third, financial crises may occur after a long period of unexpectedly loose monetary policy as the central bank abruptly reverses course.

Frederic Boissay

Centralbahnplatz, 2

CH-4002 Basel

Switzerland

frederic.boissay@bis.org

Fabrice Collard

Toulouse School of Economics

fabrice.collard@gmail.com
Jordi Galí

Centre de Recerca en Economia Internacional (CREI)

Ramon Trias Fargas 25

08005 Barcelona

SPAIN

and NBER

jgali@crei.cat

Cristina Manea

Deutsche Bundesbank

Taunusanlage 5

Frankfurt am Main 60329

Germany

cristina.manea@bundesbank.de 
"While monetary policy may not be quite the right tool for the job, it has one important advantage relative to supervision and regulation — namely that it gets in all of the cracks." (Stein (2013))

\section{Introduction}

The effect of monetary policy on financial stability is ambivalent. On the one hand, loose monetary policy can help stave off financial crises. In response to the Covid-19 shock, for example, central banks swiftly lowered interest rates and acted as a backstop to the financial sector. These moves likely prevented a financial collapse that would otherwise have exacerbated the damage to the economy. On the other hand, empirical evidence shows that, by keeping their policy rates too low for too long, central banks may entice the financial sector to search for yield and feed macro-financial imbalances 1 Loose monetary policy is thus sometimes regarded as one of the causes of the 2007-8 Great Financial Crisis (GFC). Taylor (2011), in particular, refers to the period 2003-2005 in the US as the "Great Deviation", which he characterizes as one when monetary policy became less rule-based, less predictable, and excessively loose.

This ambivalence prompts the question of the adequate monetary policy in an environment where credit markets are fragile and financial crises may have multiple causes ${ }^{2}$ What are the channels through which monetary policy affects financial stability? Should central banks deviate from their objective of price stability to promote financial stability? To what extent may monetary policy itself brew financial vulnerabilities? We study these questions within a novel New Keynesian (NK) model, where crises may arise endogenously, after a protracted boom or in the face of adverse non-financial shocks. Further, to precisely identify the effects of monetary policy, we abstract from any other type of policy, such as tax or macroprudential policies 3

Our model departs from the textbook - three-equation- NK model in four important ways. First, it features endogenous capital accumulation, so that the economy may deviate persistently from its steady state and feature protracted booms and macro-financial imbalances. Second, firms are subject to idiosyncratic productivity shocks, in addition to aggregate ones. This heterogeneity gives rise to capital reallocation between productive and unproductive firms via a credit market $4^{4}$ Third, we introduce financial frictions that make this credit market fragile.

\footnotetext{
${ }^{1}$ Empirical evidence on the potential adverse effects of loose monetary policy on financial stability can be found in e.g., Maddaloni and Peydró (2011), Jiménez, Ongena, Peydró, and Saurina (2014).

${ }^{2}$ The Federal Reserve and European Central Bank (ECB)'s recent strategy reviews both emphasize that the importance of financial stability considerations in the conduct of monetary policy has increased since the Great Financial Crisis (Goldberg, Klee, Prescott, and Wood $(2020)$, ECB $(2021)$, Schnabel (2021)).

${ }^{3}$ In this paper, we consider financial stability risks emanating from the fragility of credit markets ("market runs"), as opposed to those emanating from the fragility of financial institutions (e.g. "bank runs"). In our case, macroprudential policies that apply to financial institutions are therefore less relevant. Another reason for abstracting from macroprudential policies is that they may not always offer full protection against financial stability risks, for example if they prompt regulatory arbitrage or the emergence of shadow banks.

${ }^{4}$ One may interpret this credit market as a disintermediated corporate bond market or as an intermediated loan market, where banks would stand in-between buyers and sellers, the former taking bank loans to buy capital goods and the latter depositing the proceeds of the sales into the banks. Provided that banks are not themselves
} 
One friction is that investors may not be able to seize the wealth of a defaulting borrower, thus allowing firms to borrow and abscond. This limited enforcement problem induces investors to constrain the amount of funds that each firm can borrow. Another friction is that idiosyncratic productivities are private information. Together, these frictions imply that the loan rate must be above a minimum threshold to entice the least productive firms to lend - rather than borrow. When the marginal return on capital is too low, not even high-productivity firms can afford paying the minimum loan rate and the credit market collapses. This is what we call a financial crisis. Most crises in our model break out toward the end of a protracted economic boom, when there is excess capital in the economy and the marginal productivity of capital is low. Crises are also characterized by capital misallocation and a severe recession. Finally, the fourth departure from the textbook model is that we solve our model globally, which allows us to capture the non-linearities embedded in the endogenous booms and busts of the credit market.

We study whether monetary policy can tame such booms and busts and, more generally, whether a central bank should deviate from its objective of price stability to promote financial stability. In the process, we compare the performance of the economy under simple linear interest rate rules, non-linear rules, and discretion. Our main findings are threefold.

First, monetary policy affects the probability of a crisis not only in the short run through its usual effects on output and inflation, but also in the medium run through its effects on capital accumulation. In particular, policies that systematically dampen output fluctuations tend to slow down the accumulation of savings. The lower saving rate stems excess capital accumulation and helps prevent financial crises. As these effects go through agents' expectations, they require that the central bank commit itself to a policy rule, and only materialize themselves in the medium run.

Second, a central bank can increase welfare by departing from strict inflation targeting (henceforth, SIT) and responding systematically to fluctuations in output. For example, we show that welfare may be higher under a Taylor-type rule, whereby the central bank responds to both inflation and output, than under SIT, even though the latter policy is optimal in the absence of financial frictions.

Third, we study the effects of discretionary monetary policy interventions, i.e. deviations from the rule, on financial stability. We show that financial crises may occur after a long period of unexpected monetary easing and that, in those instances, they break out when the central bank reverses course and abruptly raises its policy rate.

At last, we discuss the welfare gain of following more complex — but perhaps less realisticmonetary policy rules, whereby the central bank commits itself to doing whatever it takes whenever needed to forestall a crisis. We find that such policy significantly improves welfare but also increases the fragility of the financial sector, forcing the central bank to backstop the financial sector relatively often.

subject to financial frictions, adding banks is inessential and will not change anything to our results. Abstracting from banks, though, makes clear that entity-based regulations or policies may not suffice to contend with credit markets' intrinsic fragility $($ Stein $(2013))$. 
The paper bridges two main strands of the literature. The first is on monetary policy and financial stability. Like Woodford (2012) and Gourio, Kashyap, and Sim (2018), we introduce endogenous crises in a standard NK framework. 5 The main difference is that they use reduced forms to determine how macro-financial variables (e.g. credit gap, credit growth, leverage) affect the likelihood of a crisis, whereas in our case financial crises - including their probability and size - are microfounded and derived from first principles. This has important consequences in terms of the prescriptions of the model. One is that, in our model, monetary policy also influences the size of the recessions that follow crises, and therefore the associated welfare cost. Another is that, even though crises can be seen as credit booms "gone wrong", as documented in Schularick and Taylor (2012), not all booms are equally "bad" and conducive to crises in our model (see also Gorton and Ordoñez (2019)) - a key element to determine how hard to lean against booms. More generally, our findings do not depend on any postulated reduced functional form for the probability of a crisis. In this sense, our model can be seen as a canonical NK model with endogenous financial crises that provides microfoundations to existing models such as Woodford (2012) and Svensson (2017). The second strand of the literature relates to quantitative macro-financial models with microfounded endogenous financial crises Gertler and Kiyotaki (2015), Boissay, Collard, and Smets (2016), Gertler, Kiyotaki, and Prestipino (2019)).6 The novelty here is that we use our model to study the link between monetary policy and financial stability. Ours also complements existing work (e.g. Gertler and Kiyotaki (2015), Gertler, Kiyotaki, and Prestipino (2019)) in that it focusses on the fragility of financial markets, as opposed to institutions, and highlights excess savings and capital accumulation (instead of excess bank leverage) as a source of fragility.

Our paper also belongs to the literature on the transmission of monetary policy in heterogeneous agent New Keynesian (HANK) models. Most existing HANK models focus on household heterogeneity and study the channels through which this heterogeneity shapes the effects of monetary policy on aggregate demand (Guerrieri and Lorenzoni (2017), Kaplan, Moll, and Violante (2018), Auclert (2019), Debortoli and Galí (2021)). In contrast, our model is on the effects of firm heterogeneity (as in Adam and Weber (2019), Manea (2020), Ottonello and Winberry (2020) $)$ and the role of credit markets in channelling resources to the most productive firms.

Though in a more indirect way, our paper is also connected to recent works on how changes in monetary policy rules affect economic outcomes in the medium term (e.g. Borio, Disyatat, and Rungcharoenkitkul (2019), Beaudry and Meh (2021)) as well as to works on the link between firms' financing constraints and capital misallocation (Eisfeldt and Rampini (2006)). In particular, the notion that financial crises impair capital re-allocation dovetails with the narrative of the GFC in the US and the literature that shows that a great deal of the recession

${ }^{5}$ See Smets (2014) for a review of the literature as well as Bernanke and Gertler $(2000)$, Galí $(2014)$, Filardo and Rungcharoenkitkul (2016), Svensson (2017), Cairó and Sim (2018), Ajello, Laubach, López-Salido, and Nakata (2019).

${ }^{\circ}$ See also Benigno and Fornaro (2018), Paul (2020), and Dou, Lo, Muley, and Uhlig (2020) for a recent review of the literature. 
that followed the GFC can be explained by capital misallocation ( (Campello, Graham, and Harvey (2010)), Foster, Grim, and Haltiwanger (2016), Argente, Lee, and Moreira (2018)).

The paper proceeds as follows. Section 2 describes our theoretical framework, with a focus on the microfoundations of endogenous financial crises, and describes the channels through which monetary policy affects financial stability. Section 3 presents the parametrization of the model as well as the average macroeconomic dynamics around financial crises. Section 4 revisits the "divine coincidence" result and analyzes the tradeoff between price and financial stability. In Section 5. we study the effect of monetary policy shocks on financial stability as well as whether a central bank should commit itself to forestall crises. A last section concludes.

\section{Model}

Our model is an extension of the textbook NK model (Galí (2015)), with sticky prices à la Rotemberg (1982) and capital accumulation, where financial frictions give rise to occasional endogenous credit market freezes.

\section{$2.1 \quad$ Agents}

The economy is populated with a central bank, a representative household, a continuum of monopolistically competitive retailers, and a continuum of competitive intermediate goods producers (henceforth, "firms"). The only non-standard agents are the firms, which live one period, are ex ante identical but experience ex post idiosyncratic productivity shocks that prompt them to resize their capital stock and participate in a credit market.

\subsubsection{Central Bank}

The central bank sets the nominal interest rate $i_{t}$ on the risk-free bond according to the following simple policy rule:

$$
1+i_{t}=\frac{1}{\beta}\left(1+\pi_{t}\right)^{\phi_{\pi}}\left(\frac{Y_{t}}{\bar{Y}}\right)^{\phi_{y}}
$$

where $\pi_{t}$ are $Y_{t}$ and aggregate inflation and output in period $t$, and $\bar{Y}$ is the aggregate output in the stochastic steady state. The central bank implicitly targets a zero inflation rate. Throughout the paper, we experiment with different values of $\phi_{\pi}$ and $\phi_{y}$-including a Taylor-type rule with Taylor (1993)'s original parameters (henceforth, TR93), as well as with a SIT rule whereby the central bank sets the policy rate so that $\pi_{t}=0$ at all $t$.

\subsubsection{Household Sector}

The representative household is infinitely lived. In period $t$, the household supplies $N_{t}$ hours of work at nominal wage $W_{t}$, consumes a Dixit-Stiglitz consumption basket of differentiated goods $C_{t} \equiv\left(\int_{0}^{1} C_{t}(i)^{\frac{\epsilon-1}{\epsilon}} \mathrm{d} i\right)^{\frac{\epsilon}{\epsilon-1}}$, with $C_{t}(i)$ the consumption of good $i$ purchased at price $P_{t}(i)$, and invests its savings in risk-free nominal bonds $B_{t}$ and equity $Q_{t}(j)$-in units of the consumption 
basket - issued by newborn firm $j$ (with $j \in[0,1]$ ). The household can thus be seen as a venture capitalist providing startup equity funding to intermediate goods producers.

The household maximizes its expected lifetime utility:7

$$
\mathbb{E}_{0}\left[\sum_{t=0}^{\infty} \beta^{t}\left(\frac{C_{t}^{1-\sigma}-1}{1-\sigma}-\chi \frac{N_{t}^{1+\varphi}}{1+\varphi}\right)\right]
$$

subject to the sequence of budget constraints

$$
\int_{0}^{1} P_{t}(i) C_{t}(i) \mathrm{d} i+B_{t}+P_{t} \int_{0}^{1} Q_{t}(j) \mathrm{d} j \leq W_{t} N_{t}+\left(1+i_{t-1}\right) B_{t-1}+P_{t} \int_{0}^{1} D_{t}(j) \mathrm{d} j+\mathscr{X}_{t}
$$

for $t=0,1, \ldots,+\infty$, where $D_{t}(j)$ is firm $j$ 's the dividend payout (expressed in final goods), and $\mathscr{X}_{t}$ denotes lump-sum transfers ${ }^{8}$ The conditions describing the household's optimal behavior are given by (in addition to a transversality condition):

$$
\begin{aligned}
C_{t}(i) & =\left(\frac{P_{t}(i)}{P_{t}}\right)^{-\epsilon} C_{t} \quad \forall i \in[0,1] \\
\chi N_{t}^{\varphi} C_{t}^{\sigma} & =\frac{W_{t}}{P_{t}} \\
\beta\left(1+i_{t}\right) \mathbb{E}_{t}\left[\left(\frac{C_{t+1}}{C_{t}}\right)^{-\sigma} \frac{1}{1+\pi_{t+1}}\right] & =1 \\
\beta \mathbb{E}_{t}\left[\left(\frac{C_{t+1}}{C_{t}}\right)^{-\sigma}\left(1+r_{t+1}^{q}(j)\right)\right] & =1 \quad \forall j \in[0,1]
\end{aligned}
$$

where

$$
1+r_{t+1}^{q}(j) \equiv \frac{D_{t+1}(j)}{Q_{t}(j)}
$$

is firm $j$ 's real rate of return on equity and $\pi_{t+1} \equiv P_{t+1} / P_{t}-1$ is the inflation rate, with $P_{t} \equiv\left(\int_{0}^{1} P_{t}(i)^{1-\epsilon} \mathrm{d} i\right)^{\frac{1}{1-\epsilon}}$ the price of the consumption basket. Since firms are born without resources and ex ante identical, the household ultimately invests the same amount $Q_{t}$ in every firm:

$$
Q_{t}(j)=Q_{t} \quad \forall j \in[0,1]
$$

\subsubsection{Retailers}

A continuum of infinitely-lived retailers purchase intermediate goods at price $p_{t}$, differentiate them, and resell them in a monopolistically competitive environment subject to nominal price rigidities. Each retailer $i \in[0,1]$ sells $Y_{t}(i)$ units of the differentiated final good $i$ and, following Rotemberg (1982), sets its price $P_{t}(i)$ subject to adjustment costs $\frac{\varrho}{2} P_{t} Y_{t}\left(\frac{P_{t}(i)}{P_{t-1}(i)}-1\right)^{2}$, where

\footnotetext{
${ }^{7}$ The term $\mathbb{E}_{t}(\cdot)$ denotes the expectation conditional on the information set available at the end of period $t$.

${ }^{8}$ These lump-sum transfers consist of retailers' rebated profits and menu costs. Since the firms live only one period, it should be clear that those that issue equity at the end of period $t$ are not the same as those that pay dividends, and therefore that we use the same $j$ index in $Q_{t}(j)$ and $D_{t}(j)$ only to economize on notations.
} 
$Y_{t} \equiv\left(\int_{0}^{1} Y_{t}(i)^{\frac{\epsilon-1}{\epsilon}} \mathrm{d} i\right)^{\frac{\epsilon}{\epsilon-1}}$ denotes the aggregate output. The demand for final goods emanates from both the representative household and the firms, which use them as inputs to produce intermediate goods. More specifically, capital goods take the form of a basket of final goods similar to that of consumption goods, implying that firms' demand for final good $i$ at the end of period $t$ is

$$
I_{t}(i)=\left(\frac{P_{t}(i)}{P_{t}}\right)^{-\epsilon} I_{t} \quad \forall i \in[0,1]
$$

where $I_{t}$ is aggregate capital investment 9 Accordingly, retailer $i$ faces the demand schedule

$$
Y_{t}(i)=\left(\frac{P_{t}(i)}{P_{t}}\right)^{-\epsilon} Y_{t} \quad \forall i \in[0,1]
$$

where $Y_{t}(i)=C_{t}(i)+I_{t}(i)$ and $Y_{t}=C_{t}+I_{t}{ }^{10}$ Each period, the retailer chooses its price $P_{t}(i)$ and production $Y_{t}(i)$ so as to maximize its expected stream of future profits:

$$
\mathbb{E}_{0}\left[\sum_{t=0}^{\infty} \Lambda_{0, t}\left(\frac{P_{t}(i)}{P_{t}} Y_{t}(i)-\frac{(1-\tau) p_{t}}{P_{t}} Y_{t}(i)-\frac{\varrho}{2} Y_{t}\left(\frac{P_{t}(i)}{P_{t-1}(i)}-1\right)^{2}\right)\right]
$$

subject to 10 for $t=0,1, \ldots,+\infty$, where $\Lambda_{t, t+k} \equiv \beta^{k}\left(C_{t+k} / C_{t}\right)^{-\sigma}$ is the stochastic discount factor between period $t$ and $t+k$ and $\tau=1 / \varepsilon$ is a subsidy rate on the purchase of intermediate goods 11

In the symmetric equilibrium, where $Y_{t}(i)=Y_{t}$ and $P_{t}(i)=P_{t}$, the optimal price setting behavior satisfies

$$
\left(1+\pi_{t}\right) \pi_{t}=\mathbb{E}_{t}\left(\Lambda_{t, t+1} \frac{Y_{t+1}}{Y_{t}}\left(1+\pi_{t+1}\right) \pi_{t+1}\right)-\frac{\epsilon-1}{\varrho}\left(1-\frac{\mathscr{M}}{\mathscr{M}_{t}}\right)
$$

where $\mathscr{M}_{t}$ is retailers' average markup given by

$$
\mathscr{M}_{t} \equiv \frac{P_{t}}{(1-\tau) p_{t}}
$$

and $\mathscr{M} \equiv \epsilon /(\epsilon-1)$ is its (deterministic) steady state value.

\subsubsection{Intermediate Goods Producers ("Firms")}

Firms live only one period, are born at the end of period $t-1$ and die at the end of period $t$. Thus, two generations of firms overlap at the end of each period. Consider firm $j \in[0,1]$ born at the end of period $t-1$. At birth, this firm receives $P_{t-1} Q_{t-1}$ startup equity funding, which it immediately uses to buy $K_{t}$ units of capital goods. Among the latter, $(1-\delta) K_{t-1}$ are old capital goods that they purchase from the previous generation of firms, where $\delta$ is the rate of depreciation (or maintenance cost) of capital, and $I_{t-1}$ are newly produced capital goods. New capital goods are produced instantaneously and one-for-one with final goods, and are

\footnotetext{
${ }^{9}$ Since capital goods are homogenous to consumption goods, they also have the same price $P_{t}$.

${ }^{10}$ This expression is obtained under the assumption that menus costs are rebated lump-sum to the household.

${ }^{11}$ This subsidy corrects for monopolistic market-power distortions in the flexible-price version of the model.
} 
homogenous to the old capital goods (net of the depreciation and maintenance cost) 12 All capital goods are therefore purchased at price $P_{t-1}$, implying that

$$
K_{t}=Q_{t-1}
$$

At the beginning of period $t$, firm $j$ experiences an aggregate shock, $A_{t}$, as well as an idiosyncratic productivity shock, $\omega_{t}(j)$, and has access to a constant-return-to-scale technology represented by the production function (see, e.g. Eisfeldt and Rampini (2006))

$$
y_{t}(j)=A_{t}\left(\omega_{t}(j) K_{t}(j)\right)^{\alpha} N_{t}(j)^{1-\alpha}
$$

where $K_{t}(j)$ and $N_{t}(j)$ denote the levels of capital and labor that firm $j$ uses as inputs conditional on the realization of $\omega_{t}(j)$ and $A_{t}$, and $y_{t}(j)$ is the associated output. The idiosyncratic shock $\omega_{t}(j) \in\{0,1\}$ takes value 0 for a fraction $\mu$ of the firms ("unproductive") and 1 for a fraction $1-\mu$ of the firms ("productive"). We denote the set of unproductive firms by $\Omega_{t}^{u} \equiv\left\{j \mid \omega_{t}(j)=0\right\}$ and that of productive firms by $\Omega_{t}^{p} \equiv\left\{j \mid \omega_{t}(j)=1\right\}$. The aggregate shock $A_{t}$ evolves randomly according to a stationary $\operatorname{AR}(1)$ process $\ln \left(A_{t}\right)=\rho_{a} \ln \left(A_{t-1}\right)+\varepsilon_{t}^{a}$ with $\left|\rho_{a}\right|<1$ and $\varepsilon \leadsto N\left(0, \sigma_{a}^{2}\right)$.

Upon observing $\omega_{t}(j)$, firm $j$ may resize its capital stock by purchasing or selling capital goods. To fill any gap between its desired capital stock $K_{t}(j)$ and its initial (and predetermined) one, $K_{t}$, firm $j$ may borrow or lend on a credit market. The latter thus operates in lockstep with the capital goods market. If $K_{t}(j)>K_{t}$, firm $j$ borrows and uses the proceeds to buy capital goods. If $K_{t}(j)<K_{t}$, it instead sells capital goods and lends the proceeds to other firms.

Let $r_{t}^{c}$ denote the real rate on the credit market, and assume that firm $j$ buys (or sells) $\left|K_{t}(j)-K_{t}\right|$ capital goods, hires labor $N_{t}(j)$, and produces intermediate goods $y_{t}(j)$. Then, at the end of the period, this firm sells its production $y_{t}(j)$ to retailers at price $p_{t}$, pays workers the unit wage $W_{t}$, sells its un-depreciated capital $(1-\delta) K_{t}(j)$ at price $P_{t}$, and pays (or receives) $P_{t}\left(1+r_{t}^{c}\right)\left|K_{t}(j)-K_{t}\right|$ to the lenders (from borrowers). Since firm $j$ distributes its revenues as dividends $P_{t} D_{t}(j)$ (see relation (2)), one obtains

$$
P_{t} D_{t}(j)=p_{t} A_{t}\left(\omega_{t}(j) K_{t}(j)\right)^{\alpha} N_{t}(j)^{1-\alpha}-W_{t} N_{t}(j)+(1-\delta) P_{t} K_{t}(j)-P_{t}\left(1+r_{t}^{c}\right)\left(K_{t}(j)-K_{t}\right)
$$

for all $j \in[0,1]$. Implicit in 15 is the assumption that capital depreciates at the same rate $\delta$ (or must be maintained at the same cost) when firm $j$ does not produce - i.e. keeps its capital stock idle - as when it does.13 Using (7), (8), and (12)-(15), one can express firm $j$ 's real rate of return on equity as

$$
r_{t}^{q}(j)=\frac{y_{t}(j)}{(1-\tau) \mathscr{M}_{t} K_{t}}-\frac{W_{t}}{P_{t}} \frac{N_{t}(j)}{K_{t}}-\left(r_{t}^{c}+\delta\right) \frac{K_{t}(j)-K_{t}}{K_{t}}-\delta \quad \forall j \in[0,1]
$$

The objective of firm $j$ is to maximize $r_{t}^{q}(j)$ with respect to $N_{t}(j)$ and $K_{t}(j)$. We study the maximization problem of unproductive and productive firms in turn.

\footnotetext{
${ }^{12}$ Hence, $K_{t}=(1-\delta) K_{t-1}+I_{t-1}$. Given that firms live only one period, note that the inter-temporal decisions regarding capital accumulation within the intermediate good sector are, in effect, taken by the household - their shareholder.

${ }^{13}$ This assumption simply implies that the marginal return on capital of a productive firm is always strictly higher than that of an unproductive firm, as relation 22 shows.
} 
Choices of an Unproductive Firm $j \in \Omega_{t}^{u}$. In this case, firm $j$ does not produce and chooses $N_{t}(j)=0$, which implies (using 16)

$$
r_{t}^{q}(j)=r_{t}^{c}-\left(r_{t}^{c}+\delta\right) \frac{K_{t}(j)}{K_{t}} \forall j \in \Omega_{t}^{u}
$$

An unproductive firm's choice boils down to either keeping capital idle, which returns $-\delta$, or selling its capital to other firms and lending out the proceeds, which returns $r_{t}^{c}$. When $r_{t}^{c}>-\delta$, it is optimal for the firm to sell its entire capital stock, and $K_{t}(j)=0$. When $r_{t}^{c}=-\delta$, the firm is indifferent. When $r_{t}^{c}<-\delta$, the firm keeps capital idle. Since unproductive firms all take the same decisions, one obtains

$$
K_{t}(j)=K_{t}^{u} \text { and } N_{t}(j)=0 \text { and } y_{t}(j)=0 \quad \forall j \in \Omega_{t}^{u}
$$

and

$$
r_{t}^{q}(j)=r_{u, t}^{q}=r_{t}^{c}-\left(r_{t}^{c}+\delta\right) \frac{K_{t}^{u}}{K_{t}} \forall j \in \Omega_{t}^{u}
$$

where $K_{t}^{u}$ and $r_{u, t}^{q}$ denote the adjusted capital stock and real rate of return on equity of an unproductive firm.

Choices of a Productive Firm $j \in \Omega_{t}^{p}$. In this case, firm $j$ 's optimal labor demand satisfies the first order condition

$$
\frac{W_{t}}{P_{t}}=\frac{(1-\alpha) y_{t}(j)}{(1-\tau) \mathscr{M}_{t} N_{t}(j)}
$$

which rewrites as (using (14))

$$
\Phi_{t} \equiv \frac{\alpha y_{t}(j)}{K_{t}(j)}=\alpha A_{t}^{\frac{1}{\alpha}}\left(\frac{1-\alpha}{(1-\tau) \mathscr{M}_{t} \frac{W_{t}}{P_{t}}}\right)^{\frac{1-\alpha}{\alpha}}
$$

where $\Phi_{t}$ denotes the marginal product of capital for a productive firm. The last term in relation (20) emphasizes that $\Phi_{t}$ is a function of the real wage $W_{t} / P_{t}$ and retailers' markup $\mathscr{M}_{t}$ and is, therefore, taken as given by firm $j$. Using (20), firm $j$ 's real rate of return on equity in (16) rewrites as

$$
r_{t}^{q}(j)=r_{t}^{c}+\left(r_{t}^{k}-r_{t}^{c}\right) \frac{K_{t}(j)}{K_{t}} \forall j \in \Omega_{t}^{p}
$$

where

$$
r_{t}^{k} \equiv \frac{\Phi_{t}}{(1-\tau) \mathscr{M}_{t}}-\delta>-\delta
$$

denotes the marginal return on capital (net of depreciation) for a productive firm. Relation 21 implies that firm $j$ is willing to purchase as much capital as possible if $r_{t}^{c}<r_{t}^{k}$, is indifferent between purchasing and selling capital if $r_{t}^{c}=r_{t}^{k}$, and sells its entire capital stock and lends the proceeds if $r_{t}^{c}>r_{t}^{k}$. Since productive firms all take the same decisions, one obtains

$$
K_{t}(j)=K_{t}^{p} \text { and } N_{t}(j)=N_{t}^{p} \text { and } y_{t}(j)=y_{t}^{p} \quad \forall j \in \Omega_{t}^{p}
$$

and

$$
r_{t}^{q}(j)=r_{p, t}^{q}=r_{t}^{c}+\left(r_{t}^{k}-r_{t}^{c}\right) \frac{K_{t}^{p}}{K_{t}} \forall j \in \Omega_{t}^{p}
$$

where $K_{t}^{p}, N_{t}^{p}, y_{t}^{p}$, and $r_{p, t}^{q}$ denote the adjusted capital stock, labour demand, output, and real rate of return on equity of a productive firm. 


\section{$2.2 \quad$ Market Clearing}

We first consider the benchmark case of a frictionless credit market, where the idiosyncratic productivity shocks can be observed by all potential investors, and where financial contracts are fully enforceable, with no constraint on the amount that a firm can borrow. Then, we introduce financial frictions.

\subsubsection{Frictionless Credit Market}

Absent financial frictions, productive firms will borrow and purchase capital until they break even, so that (from (24) $r_{p, t}^{q}=r_{t}^{c}=r_{t}^{k}>-\delta$. In this case, $K_{t}^{u}=0$, the mass $\mu$ of unproductive firms sell their entire capital stock $K_{t}$ to the mass $1-\mu$ of productive ones,

$$
K_{t}^{p}=\frac{K_{t}}{1-\mu}
$$

and $r_{u, t}^{q}=r_{p, t}^{q}$ (from (19p). As the credit market perfectly hedges firms against idiosyncratic shocks and all capital goods are used productively, the model boils down to the textbook NK model with a representative intermediate goods firm.

\subsubsection{Frictional Credit Market}

Next, consider the case of financial frictions arising from limited commitment and asymmetric information. We assume that a firm that keeps its capital idle and sells it at the end of the period has the possibility to abscond with the proceeds of the sale. Since a firm may borrow, purchase more capital, and abscond, it cannot commit itself to paying back its debt 14 We also assume that investors do not observe a given firm $j$ 's productivity $\omega_{t}(j)$, and hence cannot assess its incentives to borrow and default. As we show next, these frictions put an upper bound on the leverage of any individual firm. 15

Suppose that an unproductive firm were to mimic a productive firm by borrowing and purchasing $K_{t}^{p}-K_{t} \geq 0$ capital goods, and then keep its capital stock idle, resell it at the end of the period, and default. Its implied payoff would be $P_{t}(1-\delta) K_{t}^{p}$. That firm will not abscond as long as this payoff is smaller than the return, $P_{t}\left(1+r_{t}^{c}\right) K_{t}$, from selling its entire capital stock and lending the proceeds - which is its best alternative option. Hence the incentive

\footnotetext{
${ }^{14}$ The assumption here is that the proceeds from the sales of capital goods at the end of period $t$ can only be concealed if the capital goods have not been used for production. One can think of the firms that produce and sell intermediate goods as firms that operate transparently, and whose revenues can easily be seized by creditors. In contrast, the firms that keep their capital idle have the possibility to "go underground" and default, which limits the enforceability of financial contracts.

${ }^{15}$ The opportunity cost of absconding is higher for productive than for unproductive firms, which therefore have more incentive to default. Since firm productivity is private information and unproductive firms may pretend they are productive, productive firms can only commit themselves to paying back their debt if they limit its amount. Such a combination of limited contract enforcement and asymmetric information is standard in the macro-finance literature (Gertler and Rogoff (1990), Azariadis and Smith (1998), Boissay, Collard, and Smets (2016) ) and needed here to occasionally cause the credit market to freeze, and hence the model economy to depart from the standard NK economy. Without asymmetric information, unproductive firms would sell their entire capital stock to productive firms. Without limited enforcement, productive firms could borrow and purchase capital until they break even, as in the frictionless credit market case.
} 
compatibility constraint that ensures that no firm defaults is

$$
P_{t}(1-\delta) K_{t}^{p} \leq P_{t}\left(1+r_{t}^{c}\right) K_{t} \Longrightarrow \frac{K_{t}^{p}-K_{t}}{K_{t}} \leq \psi_{t} \equiv \max \left\{\frac{r_{t}^{c}+\delta}{1-\delta}, 0\right\}
$$

where $\psi_{t}$ is the firm's maximum leverage ratio. As long as condition 26 is satisfied, unproductive firms will refrain from borrowing and defaulting. Importantly, the borrowing limit $\psi_{t}$ increases with $r_{t}^{c}$ : the higher the loan rate, the higher unproductive firms' opportunity cost of absconding, and hence the higher productive firms' incentive-compatible leverage.

Supply and Demand Schedules. Given relations (19) and (26), unproductive firms' aggregate credit supply, denoted $L^{S}\left(r_{t}^{c}\right)$, reads:

$$
L^{S}\left(r_{t}^{c}\right)=\mu\left(K_{t}-K_{t}^{u}\right)= \begin{cases}\mu K_{t} & \text { for } r_{t}^{c}>-\delta \\ {\left[0, \mu K_{t}\right]} & \text { for } r_{t}^{c}=-\delta \\ 0 & \text { for } r_{t}^{c}<-\delta\end{cases}
$$

When $r_{t}^{c}>-\delta$, the mass $\mu$ of unproductive firms sell their capital stock $K_{t}$ and lend the proceeds on the credit market, implying $L^{S}\left(r_{t}^{c}\right)=\mu K_{t}$. When $r_{t}^{c}=-\delta$, they are indifferent between lending or keeping their capital idle, implying $L^{S}\left(r_{t}^{c}\right) \in\left[0, \mu K_{t}\right]$. When $r_{t}^{c}<-\delta$, they keep their capital stock $K_{t}$ idle: $L^{S}\left(r_{t}^{c}\right)=0$. Similarly, productive firms' aggregate credit demand, denoted $L^{D}\left(r_{t}^{c}\right)$, is given by (using (24) and (26)):

$$
L^{D}\left(r_{t}^{c}\right)=(1-\mu)\left(K_{t}^{p}-K_{t}\right)= \begin{cases}-(1-\mu) K_{t} & \text { for } r_{t}^{c}>r_{t}^{k} \\ {\left[-(1-\mu) K_{t},(1-\mu) \psi_{t} K_{t}\right]} & \text { for } r_{t}^{c}=r_{t}^{k} \\ (1-\mu) \psi_{t} K_{t} & \text { for } r_{t}^{c}<r_{t}^{k}\end{cases}
$$

The $1-\mu$ productive firms borrow only if the net return from expanding their capital stock is positive. When $r_{t}^{c}>r_{t}^{k}$, they prefer to sell their capital and lend the proceeds rather than borrow: $L^{D}\left(r_{t}^{c}\right)=-(1-\mu) K_{t}$. When $r_{t}^{c}=r_{t}^{k}$, they are indifferent but may each borrow up to $\psi_{t}$, implying (using (26)) $L^{D}\left(r_{t}^{c}\right) \in\left[-(1-\mu) K_{t},(1-\mu) \psi_{t} K_{t}\right]$. When $r_{t}^{c}<r_{t}^{k}$, they borrow up to the limit: $L^{D}\left(r_{t}^{c}\right)=(1-\mu) \psi_{t} K_{t}$.

Credit Market Equilibrium. Figure 1 depicts the credit supply and demand schedules. Panel (a) corresponds to a situation where there is a range of interest rates for which demand exceeds supply, such that

$$
\lim _{r_{t}^{c} \nearrow r_{t}^{k}} L^{D}\left(r_{t}^{c}\right) \geq \lim _{r_{t}^{c} \nearrow r_{t}^{k}} L^{S}\left(r_{t}^{c}\right) \Longleftrightarrow r_{t}^{k} \geq \bar{r}^{k} \equiv \frac{\mu-\delta}{1-\mu}
$$

where $\bar{r}^{k}$ denotes the minimum return on investment that guarantees the existence of an equilibrium with trade ${ }^{16}$ When condition (27) holds, productive firms can afford paying the required loan rate, and there exist three possible equilibria, denoted by $E, U$, and $A$ in Figure 1 .

\footnotetext{
${ }^{16}$ This threshold can also be seen as the minimum loan rate that is required to permit and entice every unproductive firm to lend on the credit market - rather than borrow and default.
} 
In what follows, we focus on equilibria $A$ and $E$ which, unlike $U$, are stable under tatônnement 17 When (27) does not hold, $A$ is the only possible equilibrium. We describe equilibria $A$ and $E$ in turn.

Figure 1: Credit Market Equilibrium

(a) Normal Times

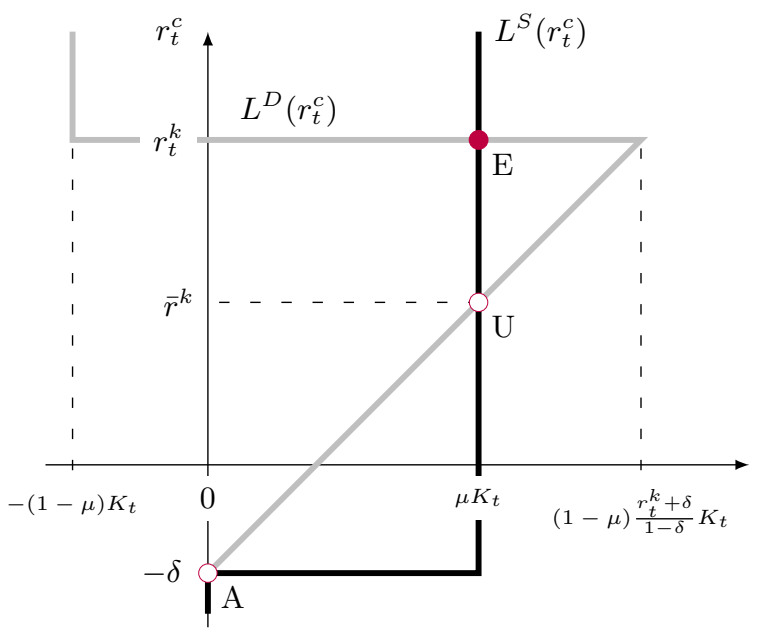

(b) Crisis Times

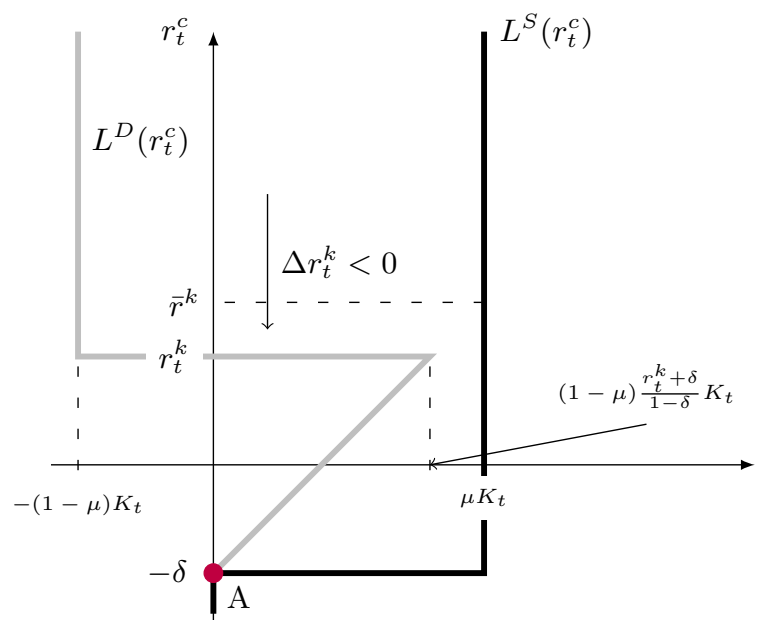

Note: This figure illustrates unproductive firms' aggregate supply on the credit market (black) and productive firms' incentive-compatible aggregate credit demand (gray) curves. In Panel (a) the demand curve is associated with a value of $r_{t}^{k}$ strictly above $\bar{r}^{k}$ and multiple equilibria $A, E$, and $U$. In this case, $U$ and $A$ are ruled out on the ground that they are unstable (for $U$ ) and Pareto-dominated (for $A$ ). In Panel $\left[\right.$ b) the demand curve is associated with a value of $r_{t}^{k}$ strictly below $\bar{r}^{k}$ and $A$ as unique equilibrium. The threshold for the loan rate, $\bar{r}^{k}$, is constant and corresponds to the minimum incentive-compatible loan rate that is required to ensure that every unproductive firm sells its entire capital stock and lends the proceeds.

Consider equilibrium $A$ (for "Autarky"), where $r_{t}^{c}=-\delta$. At that rate, unproductive firms are indifferent as lending, and therefore any supply of funds within the interval $\left[0, \mu K_{t}\right]$ is consistent with optimal firm behavior. However, the incentive compatible amount of funds that can be borrowed at that rate is zero $\left(\psi_{t}=0\right)$. As a result, $L^{D}(-\delta)=L^{S}(-\delta)=0$ and there is no trade. In what follows, we refer to this autarkic equilibrium as a "financial crisis".

Equilibrium $E$, in contrast, features a loan rate $r_{t}^{c}=r_{t}^{k} \geq \bar{r}^{k}>-\delta$, at which every unproductive firm sells capital to productive firms, as if there were no financial frictions. In that case, we have $K_{t}^{p}=K_{t} /(1-\mu)$ (see relation (25)). We refer to this equilibrium as "normal times".

Finally, consider what happens when productive firms' return on capital, $r_{t}^{k}$, falls below the threshold $\bar{r}^{k}$, so that condition (27) is not satisfied anymore. This is illustrated in Panel (b) of Figure 1. In this case, the range of loan rates for which $L^{D}\left(r_{t}^{c}\right)>L^{S}\left(r_{t}^{c}\right)$ vanishes altogether, and only the autarkic equilibrium $A$ survives.

\footnotetext{
${ }^{17}$ We rule out equilibrium $U$ because it is not tatônnement-stable. An equilibrium rate $r_{t}^{c}$ is tatônnement-stable if, following any small perturbation to $r_{t}^{c}$, a standard adjustment process - whereby the loan rate goes up (down) whenever there is excess demand (supply) of credit - pulls $r_{t}^{c}$ back to its equilibrium value (see Mas-Colell, Whinston, and Green (1995), Chapter 17). Since firms take $r_{t}^{c}$ as given, tatônnement stability is the relevant concept of equilibrium stability. Note nonetheless that $U$ and $E$ yield the same aggregate outcome and same overall return on equity $r_{t}^{q}$, and only differ in terms of productive and unproductive firms' respective returns $r_{t}^{q}(j)$ and $r_{t}^{q}(j)$.
} 
In the rest of the paper, we assume that when equilibria $A$ and $E$ coexist, market participants

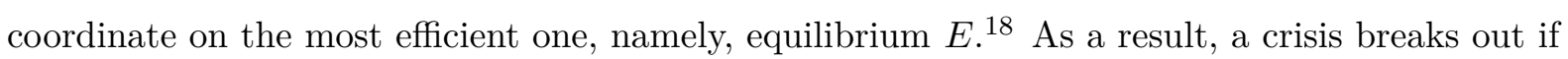
and only if $A$ is the only possible equilibrium, i.e. if and only if (27) does not hold.

\subsubsection{Other Markets}

As only productive firms hire labor and produce, the labor and intermediate goods markets clear when

$$
N_{t}=\int_{j \in \Omega_{t}^{p}} N_{t}(j) \mathrm{d} j=(1-\mu) N_{t}^{p}
$$

and

$$
Y_{t}=\int_{j \in \Omega_{t}^{p}} y_{t}(j) \mathrm{d} j=(1-\mu) y_{t}^{p}
$$

\subsection{Equilibrium Outcome}

The level of aggregate output depends on the equilibrium of the credit market. In normal times, the entire capital stock of the economy is used productively and, given $K_{t}$ and $N_{t}$, aggregate output is the same as in an economy without financial frictions (in our case, the textbook NK economy):

$$
Y_{t}=A_{t} K_{t}^{\alpha} N_{t}^{1-\alpha}
$$

In crisis times, in contrast, unproductive firms keep their capital idle, only a fraction $1-\mu$ the economy's aggregate capital stock is used productively, and aggregate productivity falls. For the same $K_{t}$ and $N_{t}$, output is therefore lower than in normal times:

$$
Y_{t}=A_{t}\left((1-\mu) K_{t}\right)^{\alpha} N_{t}^{1-\alpha}
$$

Even though in normal times aggregate productivity and output are the same as in an economy with a frictionless credit market given $K_{t}$ and $N_{t}$, note that the latter (and therefore output) will in general differ between the two economies. The reason is that the household and retailers respectively tend to accumulate precautionary savings and raise markups to compensate for the fall in consumption and productivity should a crisis break out - hence the difference between the two economies. The mere anticipation of a crisis thus induces the economy to drift away from the economy without financial frictions. Whether a crisis is imminent can be measured by the one-step-ahead crisis probability:19

$$
\mathbb{E}_{t-1}\left(\mathbb{1}\left\{\frac{Y_{t}}{\mathscr{M}_{t} K_{t}}<\frac{(1-\tau)(1-\delta) \mu}{\alpha(1-\mu)}\right\}\right)
$$

where $\mathbb{1}\{\cdot\}$ is a dummy variable equal to one when the inequality inside the curly braces holds (i.e. there is a crisis) and to zero otherwise.

\footnotetext{
${ }^{18}$ There are of course several — but less parsimonious - ways to select the equilibrium. For example, one could introduce a sunspot, e.g. assume that firms coordinate on equilibrium $E$ (i.e. are "optimistic") with some constant and exogenous probability whenever this equilibrium exists. It should be clear, however, that the central element of our analysis is condition (27) for the existence of $E$, not the selection of $E$ conditional on its existence. In other terms, our analysis does not hinge on the equilibrium selection mechanism that we assume.

${ }^{19}$ Expression (31) combines relations 20, 22, 23, 27), and 28), and the result that $K_{t}^{p}=K_{t} /(1-\mu)$ in normal times.
} 
Expression (31) makes clear that crises may emerge through a fall in aggregate output (the "Y-channel"), a rise in retailers' markup (the "M-channel"), or excess capital accumulation (the "K-channel"). For example, given a (predetermined) capital stock $K_{t}$, a crisis is more likely to break out following a shock that lowers output and/or increases the markup. Such a shock does not need to be large to trigger a crisis, if the economy has accumulated a large enough capital stock. Indeed, when $K_{t}$ is high, all other things equal, productive firms' marginal return on capital is low, and the credit market is fragile. As we show later, this may happen towards the end of an unusually long economic boom. In this case, even a modest change in $Y_{t}$ or $\mathscr{M}_{t}$ may trigger a crisis.

As the above discussion suggests, the central bank can affect the probability of a crisis both in the short and in the medium run. In the short run, it does so through the effect of contemporaneous changes in its policy rate on output and inflation (the $\mathrm{Y}$ - and $\mathrm{M}$-channels). For example, assume that the central bank unexpectedly raises its policy rate. On impact, all other things equal, the hike works to reduce aggregate demand and to increase retailers' markups. As a result, firms' marginal return on capital diminishes, which brings the economy closer to a crisis (as shown in expression (31)). In the medium run, in contrast, monetary policy affects financial stability through its impact on the household's saving behavior and capital accumulation (the K-channel). For example, a central bank that commits itself to systematically and forcefully responding to fluctuations in output (i.e. to a high $\phi_{y}$ ) will typically slow down capital accumulation during booms.

\section{Anatomy of a Financial Crisis}

Our model features various types of crises, whose origins may a priori range from an extreme exogenous adverse technology shock to an endogenous and protracted investment boom 20 The aim of this section is to describe the "average" dynamics around financial crises under a realistic parametrization of the model. As we shall see, the average crisis is in effect a mix of the above two polar types of crises.

\subsection{Parametrization of the Model}

We parameterize our model based on quarterly data (see Table 1) in the presence of aggregate TFP shocks and under Taylor (1993)'s original monetary policy rule (i.e. with $\phi_{\pi}=1.5$ and $\left.\phi_{y}=0.5 / 4\right) 21$ The standard parameters of the model take the usual values. The utility function is logarithmic with respect to consumption $(\sigma=1)$. The parameters of labor dis-utility are set to $\chi=0.814$ and $\varphi=0.5$ so as to normalize hours to one in the deterministic steady state and to obtain an inverse Frish labor elasticity of 2 - this is in the ballpark of the estimates

\footnotetext{
${ }^{20}$ The stylized graphical representation of the optimal capital accumulation decision rule in Figure 7.2 in the appendix illustrates these polar cases.

${ }^{21}$ In addition to supply shocks, one could naturally also consider demand shocks. One can show that, with a standard parametrization, the presence of demand shocks would affect neither the main tradeoffs relating to financial stability nor our main results. For the sake of parsimony, we therefore work with productivity shocks only and relegate the analysis with both shocks to the appendix (see Section 7.5.
} 
for industrialized countries. We set the discount factor to $\beta=0.989$, which corresponds to an annualized average return on financial assets of about $4 \%$. The elasticity of substitution between intermediate goods $\epsilon$ is set to 10 , which generates a markup of $11 \%$ in the steady state. Given this, we set the capital elasticity parameter $\alpha$ to 0.36 in order to obtain a labor income share of $64 \%$ in the steady state. We assume that capital depreciates by $6 \%$ per year $(\delta=0.015)$. We set the price adjustment cost parameter to $\varrho=105$, so that the model generates the same slope of the Phillips curve as in a Calvo pricing model with an average duration of prices of 4 quarters. The processus of the technology shock is also standard, with $\rho_{a}=0.95$ and $\sigma_{a}=0.007$.

Table 1: Parametrization

\begin{tabular}{|c|c|c|}
\hline \multicolumn{2}{|c|}{ ParameterTarget } & Value \\
\hline \multicolumn{3}{|c|}{ Preferences } \\
\hline$\beta$ & $4 \%$ annual real interest rate & 0.989 \\
\hline$\sigma$ & Logarithmic utility on consumption & 1.000 \\
\hline$\varphi$ & Inverse Frish elasticity equals 2 & 0.500 \\
\hline$\chi$ & Steady state hours equal 1 & 0.814 \\
\hline \multicolumn{3}{|c|}{ Technology and price setting } \\
\hline$\alpha$ & $64 \%$ labor share & 0.360 \\
\hline$\delta$ & $6 \%$ annual capital depreciation rate & 0.015 \\
\hline$\varrho$ & Slope of the Phillips curve as with Calvo price setting & 105.000 \\
\hline & $11 \%$ markup rate & 10.000 \\
\hline \multicolumn{3}{|c|}{ Aggregate TFP shocks } \\
\hline$\rho_{a}$ & Persistence & 0.950 \\
\hline$\sigma_{a}$ & Standard deviation of innovations (in \%) & 0.700 \\
\hline \multicolumn{3}{|c|}{ Interest rate rule } \\
\hline $\begin{array}{l}\phi_{\pi} \\
\phi_{y}\end{array}$ & Standard quarterly Taylor rule (Taylor (1993) & $\begin{array}{l}1.500 \\
0.125\end{array}$ \\
\hline \multicolumn{3}{|c|}{ Proportion of unproductive firms } \\
\hline$\mu$ & The economy spends $8 \%$ of the time in a crisis & 0.0242 \\
\hline
\end{tabular}

Compared to the textbook NK model, there is only one additional parameter: the proportion of unproductive firms $\mu$. This parameter implicitly governs the degree of asymmetric information and, therefore, the prevalence of financial frictions. Our model nests the textbook NK model, which corresponds to the case when $\mu=0$. All other things equal, the higher $\mu$, the higher the required minimum loan rate $\bar{r}^{k}$ (see relation (27)) and the higher the probability of a crisis. We set $\mu=2.42 \%$ so that the economy spends $8 \%$ of the time in a crisis in the stochastic steady state, which matches existing data on financial crises .22

\footnotetext{
${ }^{22}$ In Reinhart and Rogoff (2014), Laeven and Valencia (2018), and Baron, Verner, and Xiong (2020), for example, countries spend $6 \%$ to $12 \%$ of the time in a crisis. The gap is due to differences in the definition of a crisis, the identification of the starting and ending dates, and the country coverage. The combination of these three data sets over the period 1980-2017 (38 years) and 60 countries yields 110 financial crises of about seven quarters on average. It follows that a country spends on average $110 \times 7 /(60 \times 38 \times 4) \simeq 8 \%$ of the time in a crisis.
} 


\subsection{Average Dynamics Around Crises}

To derive the dynamics around the typical crisis, we proceed in two steps. First, we numerically solve our non-linear model using a global method 23 Second, starting from the stochastic steady state, we feed the model with the productivity shocks, simulate it over 1,000,000 periods, and identify the crises' starting dates as well as the sequences of shocks around them. We then compute the average dynamics 20 quarters around these dates ${ }^{24}$ The results are reported in Figure 2

Figure 2: Average Dynamics Around Crises
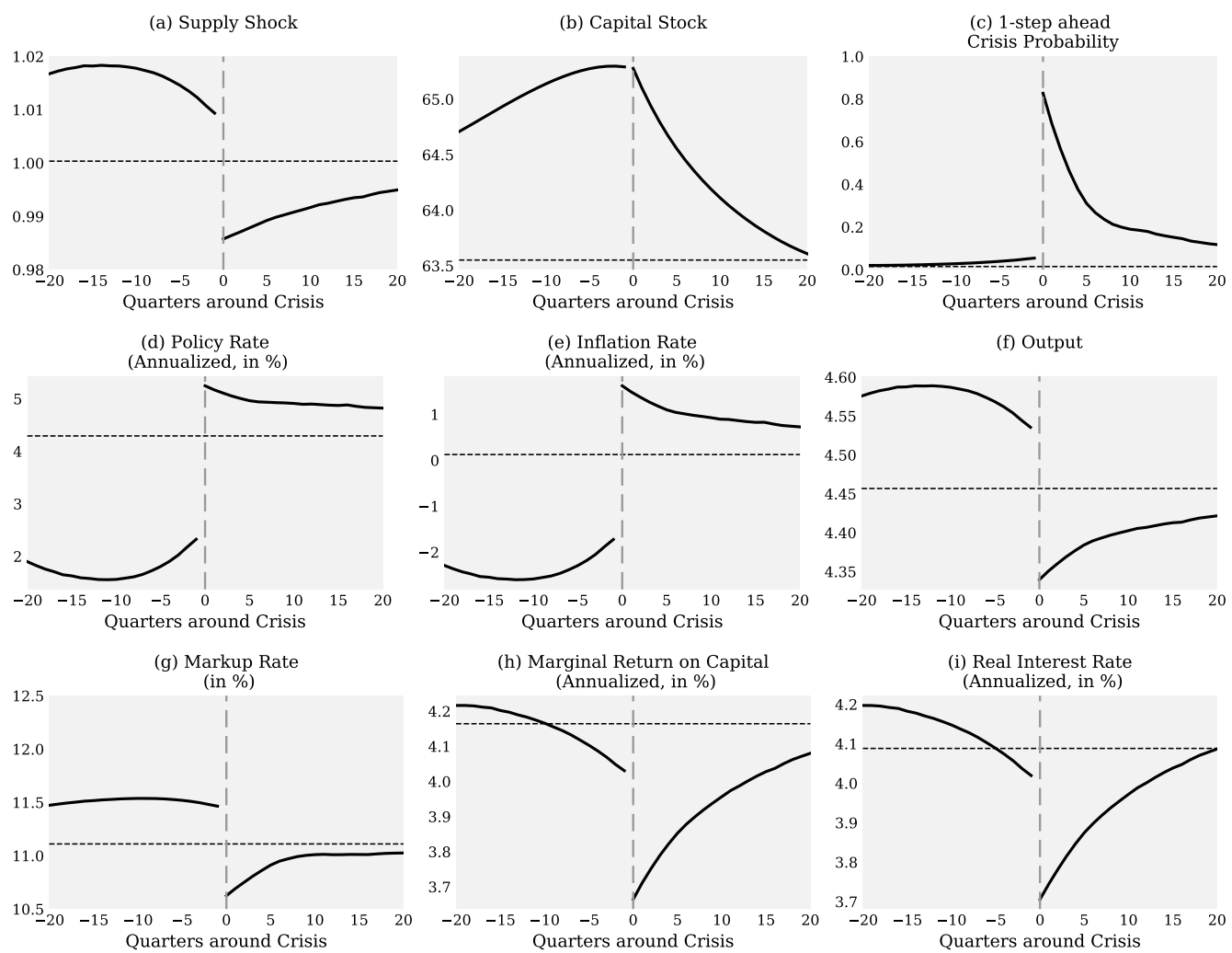

Note: Simulations for the TR93 economy. Average dynamics of the economy around the beginning of a crisis (in quarter 0 ). To filter out the potential noise due to the aftershocks of past crises, we only report averages for new crises, i.e. crises that follow at least 20 quarters of normal times. The dashed line corresponds to the unconditional average across simulation.

The main insight from the analysis is that the average crisis occurs on the heels of a protracted economic boom (Figure 2, Panels (b) and (f)) driven by a long sequence of relatively small positive technology shocks (Panel (a)). Throughout the boom, the economy accumulates capital (Panel (b)), which over time gradually exerts downward pressures on productive firms' marginal return on capital (Panel (h)). At first, these pressures are more than compensated by the

\footnotetext{
${ }^{23}$ Our model cannot be solved linearly because of discontinuities in the decision rules. It cannot be solved locally because crises may break out when the economy is far away from its steady state (e.g. when $K_{t}$ is high). Details on the numerical solution method are provided in Section 7.7 in the appendix.

${ }^{24}$ Further note that the average dynamics mask the heterogeneity and multiple causes of financial crises in our model, which can generate different types of crises, ranging from "exogenous" ones — due to large adverse shocksto "endogenous" ones — due to an investment boom. See Section 7.2 for a discussion.
} 
productivity gains, the credit market reallocates capital effectively to the most productive firms, and the probability of a crisis is relatively small (Panel (c)). As the sequence of favorable TFP shocks runs its course, productivity recedes and output falls back toward its steady state, leaving firms with excess capital. As a result, firms' marginal return on capital goes down (Panel (h)) and the probability of a crisis goes up (Panel (c)). The crisis eventually breaks out in the face of an adverse shock (of about three standard deviations) that lowers TFP by around $1.5 \%$ (about two standard deviations) below its steady state (Panel (a)). Note that this shock is not the only cause of the crisis, in the sense that the same shock would not have led to a crisis, had the capital stock been lower in the first place ${ }^{25}$ As condition (31) suggests, a capital overhang is indeed a pre-condition for a financial crisis to break out without an extreme shock. The crisis is characterized by the collapse of the credit market, capital misallocation, a recession (Panel (f)), and inflationary pressures (Panel (e)) ${ }^{26}$

The reason why crises break out even though they lead to an inefficient outcome is that neither the household nor retailers internalize the effects of their individual choices on financial fragility. To hedge against the future recession and smooth consumption, the household tends to accumulate savings, which contributes to increasing capital even further above what would be necessary to avert the crisis. Boissay, Collard, and Smets (2016) refer to this phenomenon as a "the savings glut" externality. Similarly, retailers anticipate that productivity will fall and that prices will rise during the crisis (Panel (e)). To smooth their menu costs over time, they therefore tend to front-load their price increases ahead of the crisis, which contributes to maintaining high markups and further fosters financial fragility ${ }^{27}$ The upshot is that anticipating the crisis paradoxically induces agents to precipitate — rather than avert - it. These externalities call for policy intervention, which we study next.

\section{The "Divine Coincidence" Revisited}

We now study whether central banks should account for financial stability risks when setting their policy rate. To do so, we compare welfare under different Taylor-type rules with that under SIT.

\footnotetext{
${ }^{25}$ Note that the average dynamics around crises in Figure 2 mask the heterogeneity of financial crises in our model, and notably the prevalence of boom-driven crises over shock-driven ones. For a detailed discussion, see Section 7.2 of the appendix.

${ }^{26}$ In a crisis, the adverse TFP shock and capital misallocation both entail aggregate productivity losses and inflationary pressures, which prompt the central bank to raise its policy rate. The latter result is an artifact of TFP shocks being the only aggregate shocks in the economy. One can show that, in an economy with both TFP and demand shocks, the average crisis is triggered by both types of shock, and that the fall in aggregate demand during a crisis mitigates the inflationary pressures. In such an economy, the central bank following TR93 would lower its policy rate during a crisis. For more details, see Section 7.5 in the appendix.

${ }^{27}$ These "markup externalities" come on the top of the usual aggregate demand externalities (Blanchard and Kiyotaki (1987)) and are due to the presence of financial frictions. Figure 7.4 in the appendix illustrates the incidence of the savings glut and markup externalities under a standard Taylor rule. The experiment consists in comparing the dynamics of capital and markups before the average crisis, i.e. between quarters -20 and -1 , with their dynamics in an economy without financial frictions - and fed with the very same shocks. The latter counterfactual dynamics indicate how capital and markups would have evolved absent financial frictions. Since the credit market functions equally well in the two economies between quarters -20 and -1 , the difference pins down the pure effect of crisis expectations. The bottom panels of Figure 7.4 show that the differences are positive, which means that capital and markups increase by more during the boom when the household and retailers anticipate a crisis.
} 
We use SIT as benchmark because, in the absence of financial frictions, this rule concomitantly eliminates inefficient fluctuations in the output gap - the so-called "divine coincidence"- and is optimal (Blanchard and Galí (2007)). ${ }^{28}$ We are interested in whether the central bank should depart from this benchmark in an environment where the credit market is fragile.

As a first step, we establish that SIT does not deliver the first best allocation in that environment, as the welfare loss under SIT amounts to $0.11 \%$ in terms of consumption equivalent variation (CEV), as shown in Table 2 (column "CEV ${ }^{F B}$ "). Since the distortions due to sticky prices are fully neutralized under SIT, these welfare losses are entirely due to the cost of financial crises.

Table 2: Economic Performance and Welfare under Alternative Policy Rules

\begin{tabular}{|c|c|c|c|c|c|c|c|c|}
\hline \multirow[b]{2}{*}{ Rule } & \multirow[b]{2}{*}{$\phi_{y}$} & \multirow{2}{*}{$\begin{array}{c}\text { Frictionless } \\
\mathrm{CEV}^{S I T} \\
(\%)\end{array}$} & \multicolumn{6}{|c|}{ Frictional credit market } \\
\hline & & & $\begin{array}{c}\mathrm{CEV}^{S I T} \\
(\%)\end{array}$ & $\begin{array}{c}\mathrm{CEV}^{F B} \\
(\%)\end{array}$ & $\begin{array}{c}\text { Crisis } \\
\text { time }(\%)\end{array}$ & $\begin{array}{l}\text { Length } \\
\text { (quarter) }\end{array}$ & $\begin{array}{l}\text { Output } \\
\text { loss }(\%)\end{array}$ & $\mathbb{E}\left(\pi_{t}^{2}\right)$ \\
\hline SIT & - & - & - & -0.1114 & 9.85 & 5.91 & -5.78 & 0.0000 \\
\hline \multirow{6}{*}{ 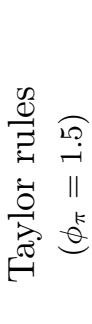 } & 0.025 & -0.0000 & -0.0072 & -0.1198 & 10.47 & 5.94 & -5.75 & 0.0004 \\
\hline & 0.050 & -0.0001 & -0.0012 & -0.1137 & 9.87 & 5.80 & -5.53 & 0.0012 \\
\hline & 0.125 & -0.0009 & 0.0160 & -0.0964 & [8.00] & 5.31 & -4.94 & 0.0064 \\
\hline & 0.250 & -0.0037 & 0.0415 & -0.0706 & 5.00 & 4.58 & -4.24 & 0.0200 \\
\hline & 0.500 & -0.0116 & 0.0652 & -0.0466 & 1.39 & 3.64 & -3.16 & 0.0516 \\
\hline & 0.750 & -0.0197 & 0.0649 & -0.0467 & 0.45 & 4.49 & -2.45 & 0.0817 \\
\hline
\end{tabular}

Note: Statistics of the stochastic steady state ergodic distribution. "Crisis time" is the percentage of the time that the economy spends in a crisis (in \%). "Length" is the average duration of a crisis (in quarters). "Output loss" is the percentage fall in output from one quarter before the crisis until the trough of the crisis (in \%). The columns under $\mathrm{CEV}^{S I T}$ report the welfare gain (loss, if negative) relative to SIT under each alternative rule considered, expressed in terms of the percent consumption equivalent variation $(\mathrm{CEV})$. Similarly, the column under $\mathrm{CEV}^{F B}$ reports the welfare loss relative to the First Best. The frictionless credit market economy corresponds to a case where $\mu=0$-all else equal. In the case of the standard Taylor rule (case with $\phi_{y}=0.125$ ), the economy spends by construction $8 \%$ of the time in a crisis (square brackets; see Section 3.1).

Can welfare be raised by following a monetary policy rule other than SIT? If so, this will necessarily come at the cost of deviating from price stability, implying a tradeoff between price and financial stability. To study this question, we report in Table 2 the statistics on the incidence of crises and price volatility in the stochastic steady state of the economy, when the central bank follows Taylor-type rules that differ in terms of the response to fluctuations in output, i.e. parameter $\phi_{y}$ in relation (1). On the one hand, responding more aggressively to output significantly reduces the time spent in a crisis, from $9.85 \%$ under SIT to $0.45 \%$ under a Taylor-type rule with $\phi_{y}=0.75$ (column "Crisis time"). On the other hand, inflation is more volatile as $\phi_{y}$ goes up (last column). All in all, we find that responding to output improves welfare, provided that the central bank responds "enough". For example, permanent consumption is $0.016 \%$ higher under TR93 than under SIT (column "CEV SIT", third and fourth rows). This

\footnotetext{
${ }^{28}$ The comparison of welfare under the various policy rules in the absence of financial frictions in Table 2 (column "Frictionless credit market") illustrates this established result.
} 
contrasts with the case of frictionless credit markets, where attaching a larger weight to output stabilization is associated with a reduction in welfare (column "CEV SIT" in the case of the frictionless credit market).

To gain intuition for the above results, we start by analyzing the effects of monetary policy on the probability of a crisis. As already noted, monetary policy plays out in the medium as well as in the short run. In the medium run, leaning against investment booms helps reduce the probability of a crisis by reining in the buildup of macro-financial imbalances.

Figure 3: Medium Run Effects: Counterfactual Booms

(a) Supply Shock

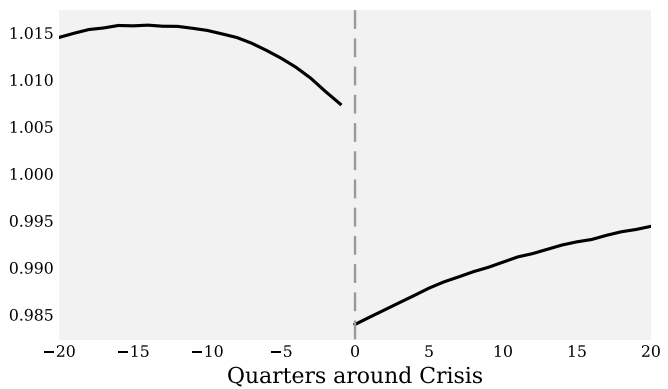

(c) Output

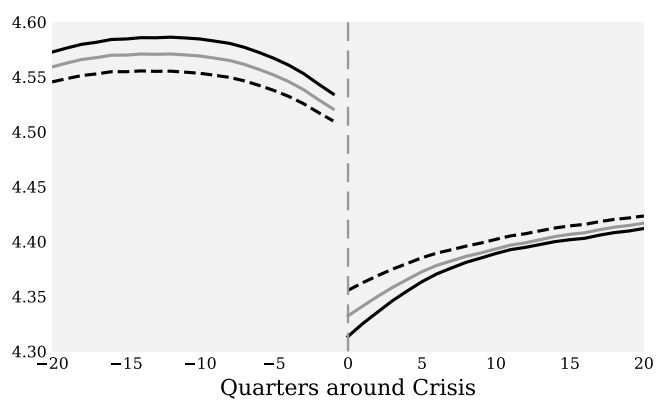

(b) Capital Stock

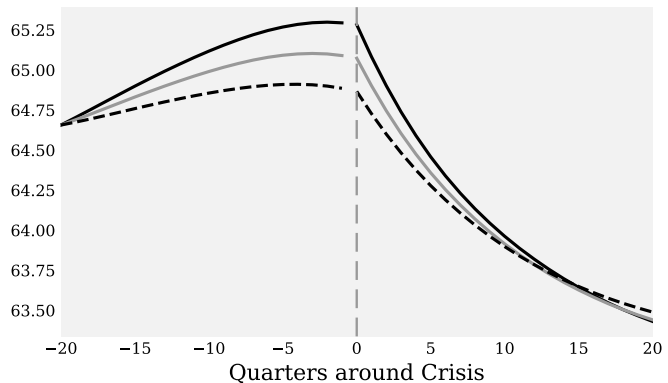

(d) Marginal Return on Capital (Annualized, in \%)

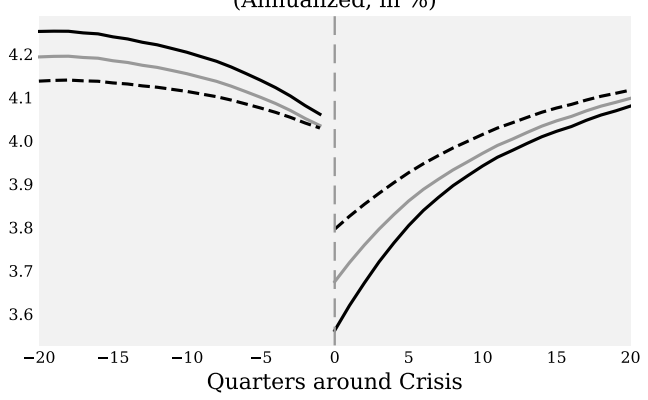

SIT $\phi_{y}=0.125(\mathrm{TR} 93)-\ldots \phi_{y}=0.25$

Notes: For SIT: average dynamics around crises. For the two Taylor-type rules with $\phi_{y}=0.125$ (TR93) or $\phi_{y}=0.25$ : counterfactual average dynamics, when the economy starts with the same capital stock in quarter $t=-20$ and is fed with the same technology shocks as the SIT economy (Panel (a)).

Figure 3 illustrates this point by comparing the average dynamics around crises under SIT with the average dynamics of the economies under Taylor-type rules, when the latter are fed with the very same sequences of shocks as those leading to a crisis under SIT (Panel (a)). These counterfactual dynamics show that capital would have been accumulated more slowly had the central bank followed - all else equal — these rules instead of SIT (Panel (b)). The reason is twofold. First, there is the usual effect of the expected rate of return of capital on capital accumulation. As the central bank commits itself to curbing growth, it also lowers investors' expected returns during booms and thus makes capital investment less attractive. Second, by smoothing the business cycle, such a policy in effect provides the household with an insurance against future aggregate shocks, and helps them smooth their consumption. This, in turn, reduces the need for precautionary savings and contributes to slowing down the accumulation of 
capital during expansions, making the economy more resilient. The upshot is that a monetary policy rule with a higher $\phi_{y}$ may lower the probability of a crisis. Because capital accumulation takes time, though, these effects only materialize over multiple years.

Monetary policy also affects the probability of a crisis through its short run macro-stabilization properties. Indeed recall that the average crisis is triggered by a standard adverse technology shock. Following such a shock, output falls by less and retailers' markups fall by more under a Taylor-type rule than under SIT, propping up firms' marginal return on capital. ${ }^{29}$ All else equal, the economy is therefore more resilient when the central bank mitigates to the fall in output.

Figure 4: The Price Versus Financial Stability Tradeofff
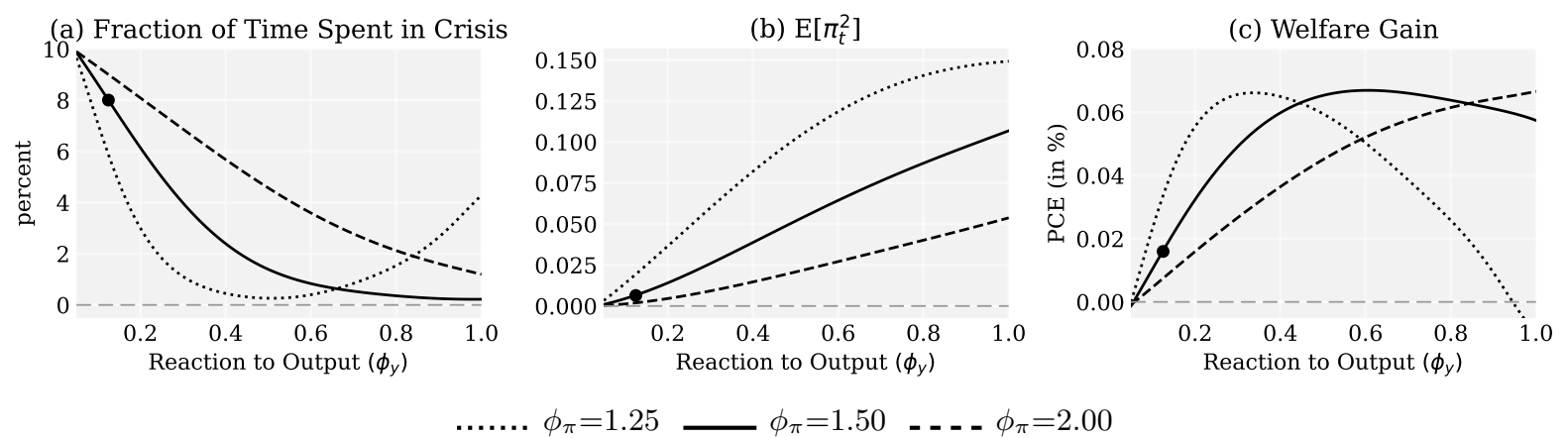

Notes: Panel (a): Time spent in a crisis (in \%, y-axis), as parameter $\phi_{y}$ increases ( $\mathrm{x}$-axis), for three different loadings on inflation: $\phi_{\pi}=1.25,1.5,2$. Panel (c): Permanent consumption equivalent increase $\left(\mathrm{CEV}^{S I T}\right.$, in \%) that the household should be given to live in the SIT economy rather than in an economy with the Taylor-type rule considered. A positive welfare gain means that welfare is higher in the TR than in the SIT economy. The black dot corresponds to our baseline calibration — where the economy spends $8 \%$ of the time in a crisis.

Last, we are interested in how hard the central bank should lean. The comparison between the last two rows of Table 2 shows that welfare is slightly lower with $\phi_{y}=0.75$ than with $\phi_{y}=0.5$, suggesting that the marginal welfare gain from leaning is decreasing. To understand this result, we present in Figure 4 the effects of raising $\phi_{y}$ on price and financial stability when the central bank follows a Taylor-type rule. For completeness, we also experiment with three different values of $\phi_{\pi}$. Consider the baseline case with $\phi_{\pi}=1.5$ first. As $\phi_{y}$ increases, the central bank stabilizes output and reduces the percentage of time in a crisis which has a positive first order effect on welfare. At the same time, raising $\phi_{y}$ works to increase the volatility of markups, as reflected in the increase in the volatility of inflation (Panel (b)). For values of $\phi_{y}>0.6$, the latter effect more than offsets the welfare gains associated with financial stability (Panel (c)).

The above price versus financial stability tradeoff is even starker when the central bank responds only mildly to inflation. When $\phi_{\pi}=1.25$ (dotted line), for example, markup volatility increases faster with $\phi_{y}$ than in the baseline case (Panel (b)). One implication is that the percentage of time the economy spends in a crisis at first falls with $\phi_{y}$ until $\phi_{y} \approx 0.55$ and then increases with $\phi_{y}$ beyond that threshold (Panel (a), dotted line). This is because, as $\phi_{y}$ goes up

\footnotetext{
${ }^{29}$ Recall that, around the steady state, our model essentially boils down to the textbook NK model with capital accumulation and, therefore, that the response of the economy to small shocks is standard. Figure 7.5 in the appendix, which compares the impulse responses to a negative one-standard deviation technology shock under SIT versus Taylor-type rules, illustrates this point.
} 
and the central bank leans harder during booms, the financial stability gain from slower capital accumulation ( $\mathrm{K}$-channel) gets more than offset by the financial stability loss due to higher markups (M-channel). It follows that, beyond a certain level (here around $\phi_{y} \approx 0.3$ ), leaning "too hard" may undermine both price and financial stability, and overall reduce welfare (Panel (c), dotted line).

\section{$5 \quad$ Alternative Monetary Policy Strategies}

\subsection{Monetary Policy Discretion and Financial Instability}

In his narrative of the GFC, Taylor (2011) argues that discretionary and loose monetary policy may have exposed the economy to financial stability risks - the "Great Deviation" view. This section revisits this narrative and assesses the potential detrimental effects of monetary shocks - as opposed to rules - on financial stability. To do so, we consider a TR93 economy that experiences random deviations from the policy rule - "monetary policy shocks" - and where these shocks are the only source of aggregate uncertainty. More specifically, we consider a monetary policy rule of the form

$$
1+i_{t}=\frac{1}{\beta}\left(1+\pi_{t}\right)^{1.5}\left(\frac{Y_{t}}{\bar{Y}}\right)^{0.125} \varsigma_{t}
$$

with two alternatives exogenous processes for the monetary policy shock $\varsigma_{t}$. One is an $\operatorname{AR}(1)$ process $\ln \left(\varsigma_{t}\right)=\rho_{\varsigma} \ln \left(\varsigma_{t-1}\right)+\epsilon_{t}^{\varsigma}$, with $\rho_{\varsigma}=0.5$ and $\sigma_{\varsigma}=0.0025$, as in Galí (2015). The other is a random independently and identically distributed (i.i.d.) shock that has the same volatility. We are interested in the dynamics of monetary policy shocks around crises in this new environment.

Figure 5: Rates Too Low for Too Long May Lead to a Crisis

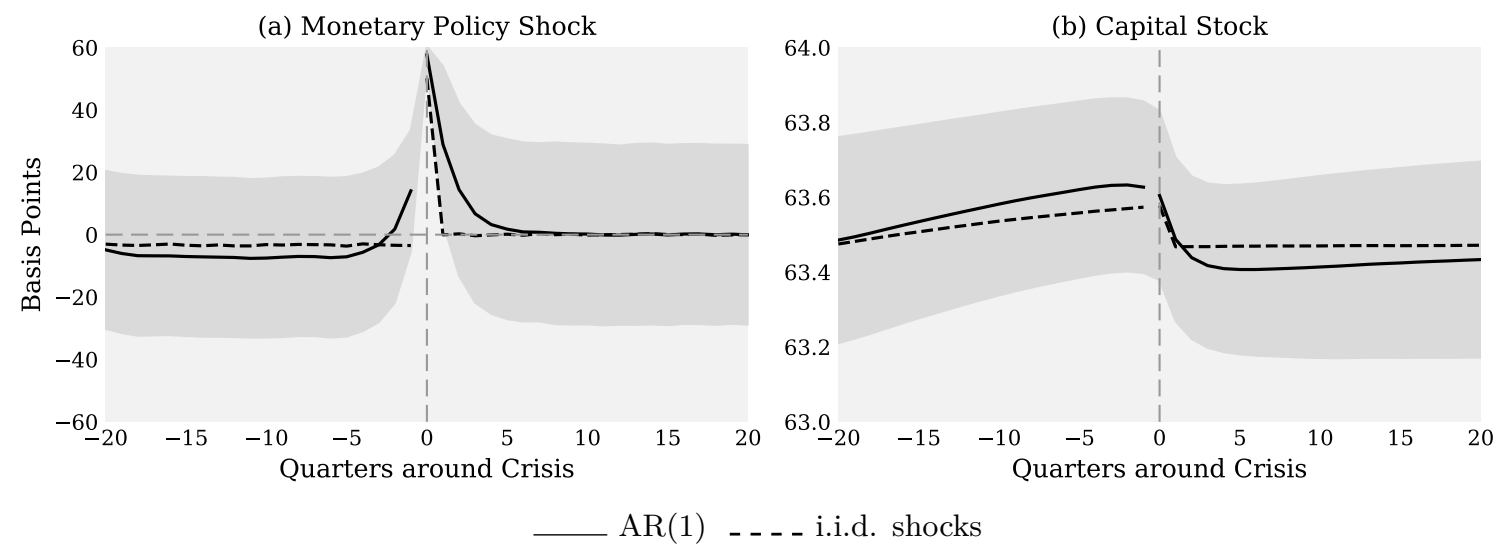

The results, reported in Figure 5, show that the average crisis breaks out following a long period of unexpected monetary easing (Panel (a)) that feeds an investment boom (Panel (b)). In other words, by keeping the policy rate too low for too long, the central bank feeds macrofinancial imbalances, leading the economy to a crisis. Moreover, the crisis is triggered by three consecutive periods of unwarranted (according to the rule) and abrupt interest rate hikes toward the end of the boom in the case of the persistent shock and a one-off 60 basis point jolt in the 
case of the i.i.d. shock. This latter finding is consistent with recent empirical evidence that unanticipated "last minute" interest rate hikes at the end of a boom are more likely to trigger a crisis than to avert it (Schularick, Ter Steege, and Ward (2021)). Overall, our analysis highlights that discretionary monetary policy may be a source of financial instability.

\subsection{Monetary Policy as Backstop}

Should the central bank systematically backstop the credit market during financial distress episodes? This section aims at evaluating the potential welfare gains from this type of policy. More precisely, we consider non-linear interest rate rules whereby the central bank commits itself to following SIT or a Taylor-type rule in normal times but also to doing whatever it takes whenever needed - and therefore exceptionally deviating from these rules - to forestall a crisis. In those instances, we assume that the central bank deviates "just enough" to avert the crisis, i.e. sets its policy rate so that $r_{t}^{k}=\bar{r}^{k}$ (see condition (27)) ${ }^{30}$ We refer to such a contingent, non-linear rule as a "backstop" rule 31

Figure 6: Backstop Interventions Required to Stave off a Crisis
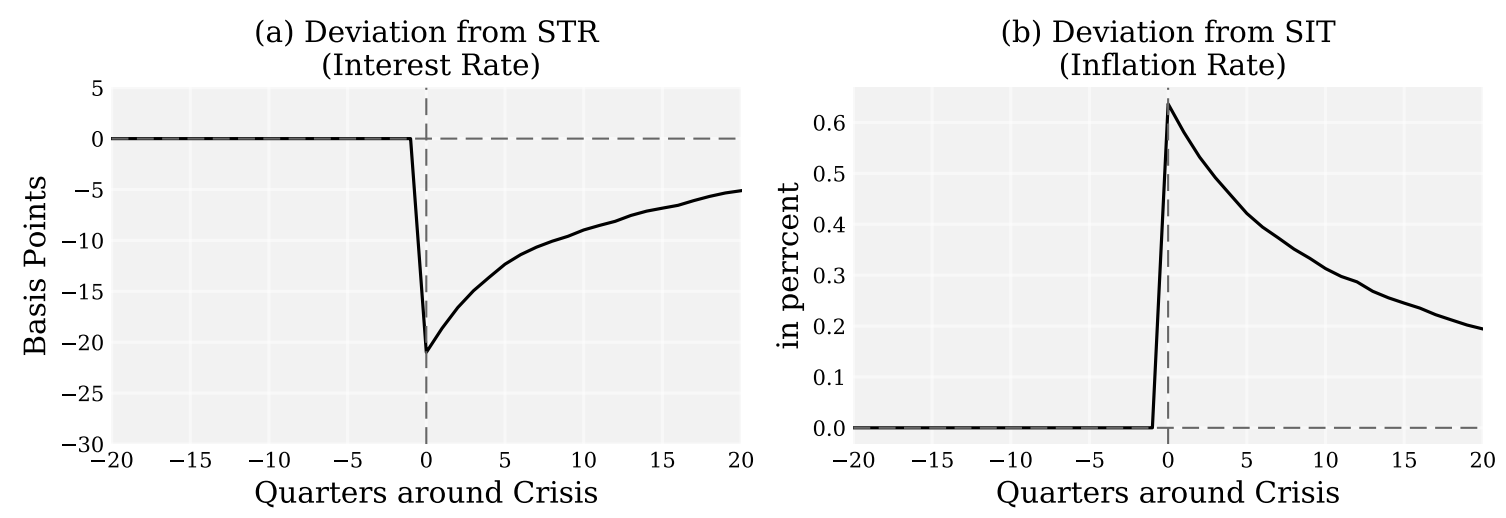

Notes: Average deviations from the normal times' policy rule that the central bank must commit itself to and implement in order to forestall financial crises. Panel (a): deviation of the policy rate, in basis points, when the central bank otherwise follows TR93. Panel (b): deviation of the inflation target from zero, in percentage point, when the central bank otherwise follows SIT.

As a first step, we show in Figure 6 the average deviations from TR93 (Panel (a)) and SIT (Panel (b)) that are needed in order to stave off a crisis. These deviations are reported in terms of the policy rate (in basis points) for TR93 and in terms of the annualized inflation rate (in percentage points) for SIT. In both cases, the central bank must loosen its policy compared to normal times, which means to lower its policy rate by 20 bps below TR93 or momentarily tolerate a $0.6 \mathrm{pp}$ higher inflation rate under SIT.

Next, we compare the welfare gain of following a backstop rule. The welfare results, reported in Table 3, are directly comparable with those in Table 2. Two findings stand out. First,

\footnotetext{
${ }^{30}$ In the case of a Taylor-type rule $1+i_{t}=\frac{1}{\beta}\left(1+\pi_{t}\right)^{1.5}\left(\frac{Y_{t}}{Y}\right)^{0.125} \varsigma_{t}$, for example, this consists in setting the term $\varsigma_{t}=1$ if $r_{t}^{k} \geq \bar{r}^{k}$, and setting $\varsigma_{t}$ such that $r_{t}^{k}=\bar{r}^{k}$ whenever $r_{t}^{k}$ would otherwise be lower than $\bar{r}^{k}$. Likewise, in the SIT case, the central bank tolerates deviations from strict inflation targeting just enough so that $r_{t}^{k}=\bar{r}^{k}$.

${ }^{31}$ Our notion of backstopping is related to, but different from, the notion of "cleaning", whereby the central bank mitigates the effects of a crisis only once it broke out.
} 
backstopping the economy improves welfare significantly over SIT (column "CEV ${ }^{S I T ") ~ a n d, ~}$ depending on the policy rule, may almost entirely eliminate the welfare cost of financial crises (column "CEV $F B$ "). In the case of the SIT rule (first row), for instance, the household should be given $0.11 \%$ more permanent consumption for living in an economy without, rather than with, backstopping — which essentially corresponds to the welfare cost of crises reported in Table 2 More generally, relative to the first best allocation, the overall welfare loss in the backstopped economies is negligible (around $0.001 \%$ ) in the case of SIT and TR93 ${ }^{32}$

Table 3: Economic Performance and Welfare Under Backstop Policies (BP)

\begin{tabular}{|c|c|c|c|c|c|c|}
\hline Rule & $\phi_{y}$ & $\begin{array}{c}\mathrm{CEV}^{S I T} \\
(\%)\end{array}$ & $\begin{array}{c}\mathrm{CEV}^{F B} \\
(\%)\end{array}$ & $\begin{array}{c}\text { BP time } \\
(\%)\end{array}$ & $\begin{array}{c}\text { Length } \\
\text { (quarter) }\end{array}$ & $\mathbb{E}\left(\pi_{t}^{2}\right)$ \\
\hline SIT & - & 0.1102 & -0.0013 & 15.16 & 8.84 & 0.0019 \\
\hline \multirow{6}{*}{ 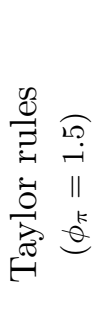 } & 0.025 & 0.1103 & -0.0012 & 17.99 & 9.17 & 0.0011 \\
\hline & 0.050 & 0.1102 & -0.0013 & 16.30 & 8.70 & 0.0017 \\
\hline & 0.125 & 0.1096 & -0.0019 & 11.81 & 7.45 & 0.0063 \\
\hline & 0.250 & 0.1071 & -0.0044 & 6.30 & 5.93 & 0.0196 \\
\hline & 0.500 & 0.0998 & -0.0117 & 1.38 & 4.43 & 0.0196 \\
\hline & 0.750 & 0.0918 & -0.0196 & 0.37 & 5.11 & 0.0821 \\
\hline
\end{tabular}

Note: Statistics of the stochastic steady state ergodic distribution. "BP time" is the percentage of the time that central bank must backstop the economy (in \%). "Length" is the average duration of the backstop policy (in quarters). The column under $\mathrm{CEV}^{S I T}$ reports the welfare gain (loss, if negative) relative to SIT under each of the backstop policy considered, expressed in terms of the percent consumption equivalent variation (CEV). Similarly, the column under $\mathrm{CEV}^{F B}$ reports the welfare loss relative to the First Best.

Second, the financial sector is paradoxically more fragile when the central bank commits itself to backstopping the economy. Under SIT, for instance, the central bank has to backstop the economy - and therefore deviate from its normal times policy rule - slightly more than $15 \%$ of the time, whereas without backstop the economy would spend less than $10 \%$ of the time in a crisis (compare the column "BP time" with the column "Crisis time" in Table 2). This greater fragility is due to backstopping episodes being both more likely and more persistent (column "Length") than crisis episodes (column "Length" in Table 2). Indeed, when the central bank backstops the economy, it eliminates the negative wealth effects associated with financial crises. All else equal, the capital stock thus tends to be on average higher in that case, which makes the credit market more vulnerable than in an economy without backstop. Moreover, when the central bank intervenes to stave off a crisis, it also slows down the downward adjustment of capital that would be necessary to eliminate the existing imbalances. As a result, financial distress lasts longer and requires the central bank to intervene over around two years in the case of SIT and TR93.

\footnotetext{
${ }^{32}$ In the case of the Taylor-type rules, welfare decreases with $\phi_{y}$ because, when the central bank backstops the economy, there is little benefit from leaning against investment booms in normal times. In this case, it is desirable that the central bank follow a rule that addresses the welfare cost of nominal rigidities in normal times - very much like in the standard NK model.
} 


\section{Conclusion}

What are the channels through which monetary policy affects financial stability? Should central banks deviate from their objective of price stability to promote financial stability? To what extent may monetary policy itself brew financial vulnerabilities? To address these questions, we have extended the textbook NK model with capital accumulation, heterogeneous firms, and a credit market that allows the economy to reallocate capital efficiently across firms. Absent frictions on the credit market, the equilibrium outcome boils down to that of the standard model with a representative firm. With financial frictions, in contrast, there is an upper bound on the leverage ratio of any individual firm resulting from an incentive-compatibility constraint, which prevents capital from being fully reallocated to the most efficient firms. When the average return on capital is too low, possibly due to a capital overhang at the end of a long boom, the credit market collapses, triggering a financial crisis and a fall in activity due to capital misallocation.

We show that conventional monetary policy affects financial stability through three main channels: in the short run, through its effects on aggregate demand and markups, and in the medium run, through its effects on capital accumulation. We also show that, by deviating from strict inflation targeting and systematically leaning against investment booms, the central bank may not only reduce the probability of a crisis but also improve welfare. Finally, we show that discretionary monetary policy actions, such as keeping policy rates too low for too long and then unexpectedly and abruptly raising them toward the end of an investment boom, can lead to a financial crisis. 


\section{References}

Adam, K., And H. Weber (2019): "Optimal Trend Inflation," American Economic Review, 109(2), 702-37.

Ajello, A., T. Laubach, D. López-Salido, and R. Nakata (2019): "Financial stability and optimal interest rate policy," International Journal of Central Banking, 15(1), 279-326.

Argente, D., M. Lee, And S. Moreira (2018): "Innovation and product reallocation in the great recession," Journal of Monetary Economics, 93, 1-20.

Auclert, A. (2019): "Monetary Policy and the Redistribution Channel," American Economic Review, 109(6), 2333-67.

Azariadis, C., AND B. SMith (1998): "Financial intermediation and regime switching in business cycles," American Economic Review, 88(3), 516-536.

Baron, M., E. Verner, and W. Xiong (2020): "Banking Crises Without Panics," The Quarterly Journal of Economics, 136(1), 51-113.

Beaudry, P., And C. Meh (2021): "Monetary policy, trends in real interest rates and depressed demand," Bank of Canada staff Working Paper No 2021-27.

Benigno, G., and L. Fornaro (2018): "Stagnation Traps," The Review of Economic Studies, $85(3), 1425-1470$.

Bernanke, B., And M. Gertler (2000): "Monetary policy and asset price volatility," NBER Working Paper No 7559.

Blanchard, O., and J. Galí (2007): "Real wage rigidities and the New Keynesian model," Journal of money, credit and banking, 39, 35-65.

Blanchard, O., and N. Kiyotaki (1987): "Monopolistic competition and the effects of aggregate demand," American Economic Review, 77(4), 647-666.

Boissay, F., F. Collard, and F. Smets (2016): "Booms and Banking Crises," Journal of Political Economy, 124(2), 489-538.

Borio, C., P. Disyatat, and Rungcharoenkitkul (2019): "Monetary policy hysteresis and the financial cycle," BIS Working Paper No 817.

Cairó, I., And J. Sim (2018): "Income Inequality, Financial Crises, and Monetary Policy," Federal Reserve Board, Finance and Economics Discussion Series, No 2018-048.

Campello, M., J. R. Graham, and C. Harvey (2010): "The real effects of financial constraints: Evidence from a financial crisis," Journal of Financial Economics, 97, 470-487. 
Christiano, L., and J. Fisher (2000): "Algorithms for Solving Dynamic Models with Occasionally Binding Constraints," Journal of Economic Dynamics and Control, 24(8), 11791232 .

Debortoli, D., and J. Galí (2021): "Monetary policy with heterogeneous agents: Insights from TANK models," Universitat Pompeu Fabra, Economics Working Papers, No 1686.

Dou, W., A. Lo, A. Muley, and H. Uhlig (2020): "Macroeconomic Models for Monetary Policy: A Critical Review from a Finance Perspective," Annual Review of Financial Economics, $12,95-140$.

ECB (2021): "The role of financial stability considerations in monetary policy and the interaction with macroprudential policy in the euro area," Occasional Paper Series \# 272.

Eisfeldt, A. L., AND A. A. RAmpini (2006): "Capital reallocation and liquidity," Journal of Monetary Economics, 53(3), 369-399.

Filardo, A., and P. Rungcharoenkitkul (2016): "A quantitative case for leaning against the wind," BIS Working Paper No 594.

Foster, L., C. Grim, and J. Haltiwanger (2016): "Reallocation in the Great Recession: Cleansing or Not?," Journal of Labor Economics, 34(S1), S296-S331.

Galí, J. (2015): Monetary policy, inflation, and the business cycle: an introduction to the New Keynesian framework and its applications. Princeton Univesity Press.

Galí, J. (2014): "Monetary Policy and Rational Asset Price Bubbles," American Economic Review, 104(3), 721-52.

Gertler, M., and N. Kiyotaki (2015): "Banking, Liquidity, and Bank Runs in an Infinite Horizon Economy," American Economic Review, 105(7), 2011-43.

Gertler, M., N. Kiyotaki, and A. Prestipino (2019): "A macroeconomic model with financial panics," The Review of Economic Studies, 87(1), 240-288.

Gertler, M., and K. Rogoff (1990): "North-South lending and endogenous domestic capital market inefficiencies," Journal of Monetary Economics, 26, 245-66.

Goldberg, J., E. Klee, E. S. Prescott, and P. Wood (2020): "Monetary policy strategies and tools: financial stability considerations," Federal Reserve Board Finance and Economics Discussion Series \# 2020-074.

Gorton, G., And G. Ordoñez (2019): "Good Booms, Bad Booms," Journal of the European Economic Association, 18(2), 618-665.

Gourio, F., A. Kashyap, And J. Sim (2018): "The trade-offs in leaning against the wind," IMF Economic Review, 66, 70-115. 
Greenwood, R., S. Hanson, A. Schleifer, and J. Ahm Sørensen (2021): "Predictable financial crises," Journal of Finance, forthcoming.

Guerrieri, V., and G. Lorenzoni (2017): "Credit Crises, Precautionary Savings, and the Liquidity Trap," The Quarterly Journal of Economics, 132(3), 1427-1467.

Jiménez, G., S. Ongena, J.-L. Peydró, and J. Saurina (2014): "Hazardous times for monetary policy: what do twenty-three million bank loans say about the effects of monetary policy on credit risk-taking?," Econometrica, 82(2), 463-505.

Kaplan, G., B. Moll, and G. L. Violante (2018): "Monetary Policy According to HANK," American Economic Review, 108(3), 697-743.

Laeven, L., and F. Valencia (2018): "Systemic Banking Crises Revisited," IMF Working Papers.

Maddaloni, A., and J.-L. Peydró (2011): "Bank Risk-taking, Securitization, Supervision, and Low Interest Rates: Evidence from the Euro-area and the U.S. Lending Standards," The Review of Financial Studies, 24(6), 2121-2165.

MANEA, C. (2020): "Monetary policy with financially constrained and unconstrained firms," Essays in Monetary Economics, PhD Thesis, Universitat Pompeu Fabra.

Mas-Colell, A., M. Whinston, And J. Green (1995): Microeconomic Theory. Oxford university Press.

Ottonello, P., and T. Winberry (2020): "Financial Heterogeneity and the Investment Channel of Monetary Policy," Econometrica, 88(6), 2473-2502.

PAul, P. (2020): "A macroeconomic model with occasional financial crises," Journal of Economic Dynamics and Control, 112.

Reinhart, C., And K. Rogoff (2014): "This time is different: a panoramic view of eight centuries of financial crises," Annals of Economics and Finance, pp. 215-268.

Rotemberg, J. J. (1982): "Monopolistic Price Adjustment and Aggregate Output," The Review of Economic Studies, 49(4), 517-531.

Rouwenhorst, K. (1995): Asset Pricing Implications of Equilibrium Business Cycle Modelspp. 294-330. Princeton University Press, Princeton.

Schnabel, I. (2021): "A new strategy for a changing world," Speech at the Peterson Institute for International Economics's virtual Financial Statements Series.

Schularick, M., and A. M. Taylor (2012): "Credit Booms Gone Bust: Monetary Policy, Leverage Cycles, and Financial Crises, 1870-2008," American Economic Review, 102(2), 1029-61. 
Schularick, M., L. Ter Steege, and F. Ward (2021): "Leaning against the wind and crisis risk," American Economic Review: Insights, (forthcoming).

Smets, F. (2014): "Financial stability and monetary policy: how closely interlinked?," International Journal of Central Banking, 10, 263-300.

Smets, F., And R. Wouters (2007): "Shocks and Frictions in US Business Cycles: A Bayesian DSGE Approach," American Economic Review, 97(3), 586-606.

Stein, J. (2013): "Overheating in Credit Markets: Origins, Measurement, and Policy Responses," Remarks at "Restoring Household Financial Stability after the Great Recession: Why Household Balance Sheets Matter" Research Symposium, Federal Reserve Bank of St. Louis, St. Louis, Missouri.

Svensson, L. E. (2017): "Cost-benefit analysis of leaning against the wind," Journal of Monetary Economics, 90, 193-213.

TAYlor, J. (1993): "Discretion versus policy rules in practice," Carnegie-Rochester Conference Series on Public Policy, 39, 195-214.

(2011): Macroeconomic Lessons from the Great Deviation, vol. 25 of NBER Macroeconomics Annual. University of Chicago Press.

Woodford, M. (2012): "Inflation targeting and financial stability," Sveriges Riksbank Economic Review, 1, 1-32. 


\section{Appendix}

\subsection{Frictionless Credit Market Equilibrium}

Figure 7.1 presents unproductive firms' aggregate credit supply (black) and productive firms' incentive-compatible aggregate demand (gray) curves in the absence of financial frictions (see Section 2.2.1). In this case, equilibrium $E$ is unique and, given $r_{t}^{k}$, the same as equilibrium $E$ that would prevail in normal times in the presence of financial frictions (see Figure 1, panel (a)).

Figure 7.1: Frictionless Credit Market Equilibrium

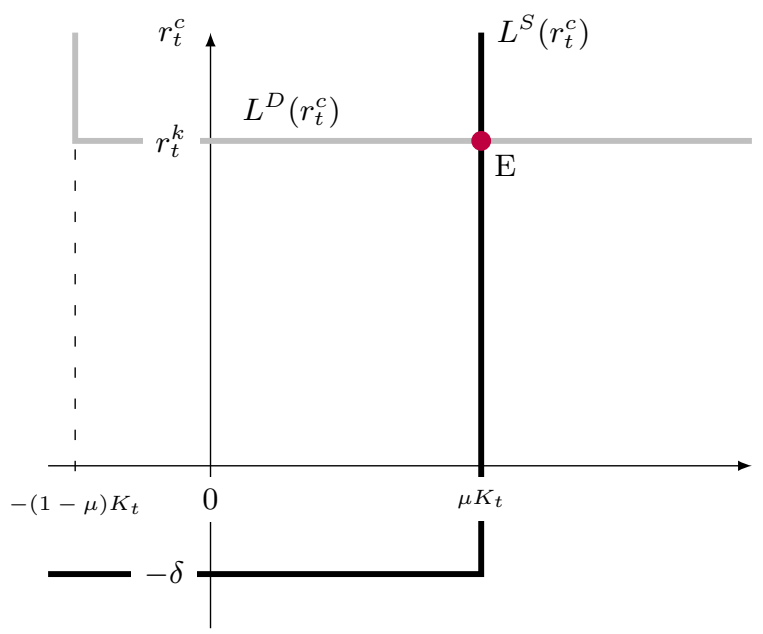

Note: This figure illustrates unproductive firms' aggregate credit supply (black) and productive firms' aggregate loan demand (gray) curves, in the absence of financial frictions.

\subsection{Financial Crises: Polar Types and Multiple Causes}

Figure 7.2 is a stylized representation of the optimal capital accumulation decision rule, which expresses $K_{t+1}$ as a function of state variables $K_{t}$ and $A_{t}$. During a crisis, the household dis-saves to consume, which generates less investment and a fall in the capital stock, as captured by the discontinuous downward breaks in the decision rules. There are two polar types of crises. The first one can be - loosely - characterized as "exogenous": for a given level of capital stock $K_{t}^{\text {average }}$, a crisis breaks out when productive firms' marginal return on capital, $r_{t}^{k}$, falls below the required incentive compatible loan rate, $\bar{r}^{k}$ (condition (27)). In Figure 7.2, this is the case in equilibrium $\mathrm{A}_{\text {exog }}$, where aggregate productivity $A_{t}$ falls from $A_{t}^{\text {average }}$ to $A_{t}^{\text {low }}$. The other polar type of crisis can be - loosely - characterized as "endogenous": following an unexpectedly long period of high productivity $A_{t}^{\text {high }}$, the household accumulates savings and feeds an investment boom that increases the stock of capital. All other things equal, the rise in the capital stock reduces productive firms' marginal return on capital until $r_{t}^{k}<\bar{r}^{k}$. The crisis then breaks out

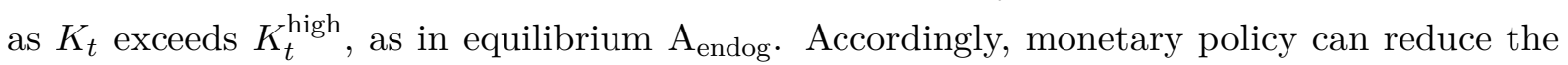
incidence of financial crises either by dampening the effects of shocks through a macro-economic stabilization policy (via the Y- or M-channel), or by improving the resilience of the economy by slowing down capital accumulation during booms (via notably the $\mathrm{K}$-channel), or by doing both. 
Figure 7.2: Optimal Decision Rules $K_{t+1}\left(K_{t}, A_{t}\right)$ and Two Polar Types of Crisis

Crisis due to capital overhang fol-

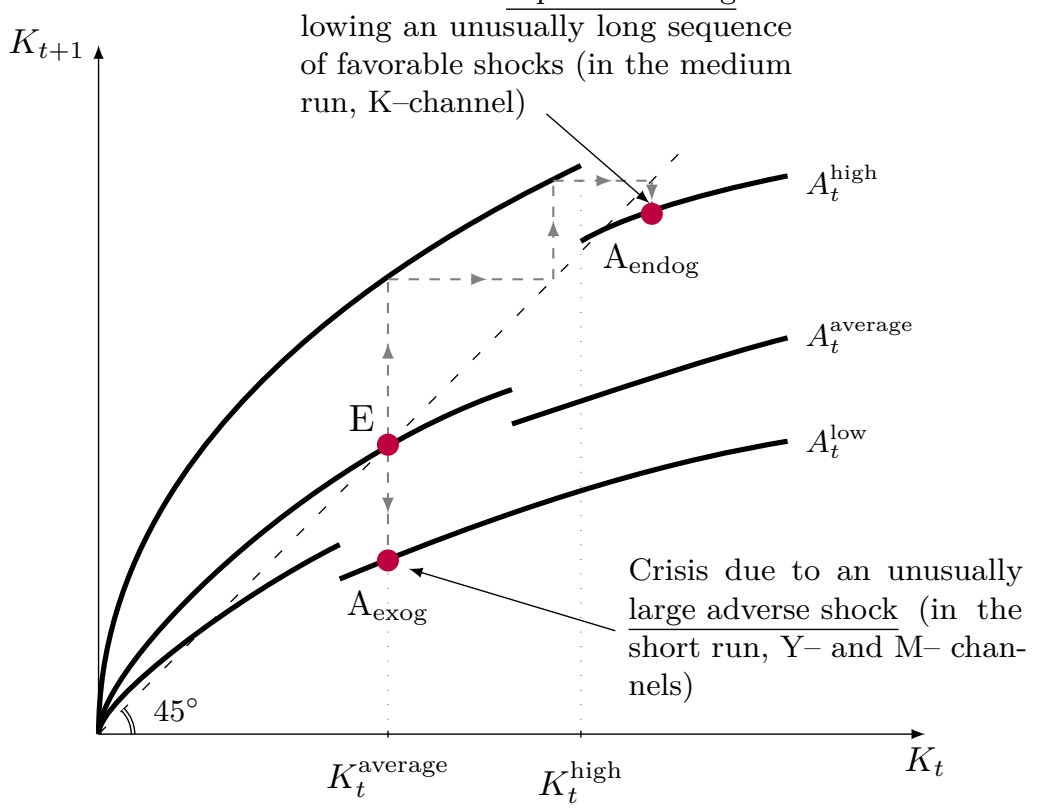

Figure 7.3: Predicted Versus Unpredicted Financial Crises
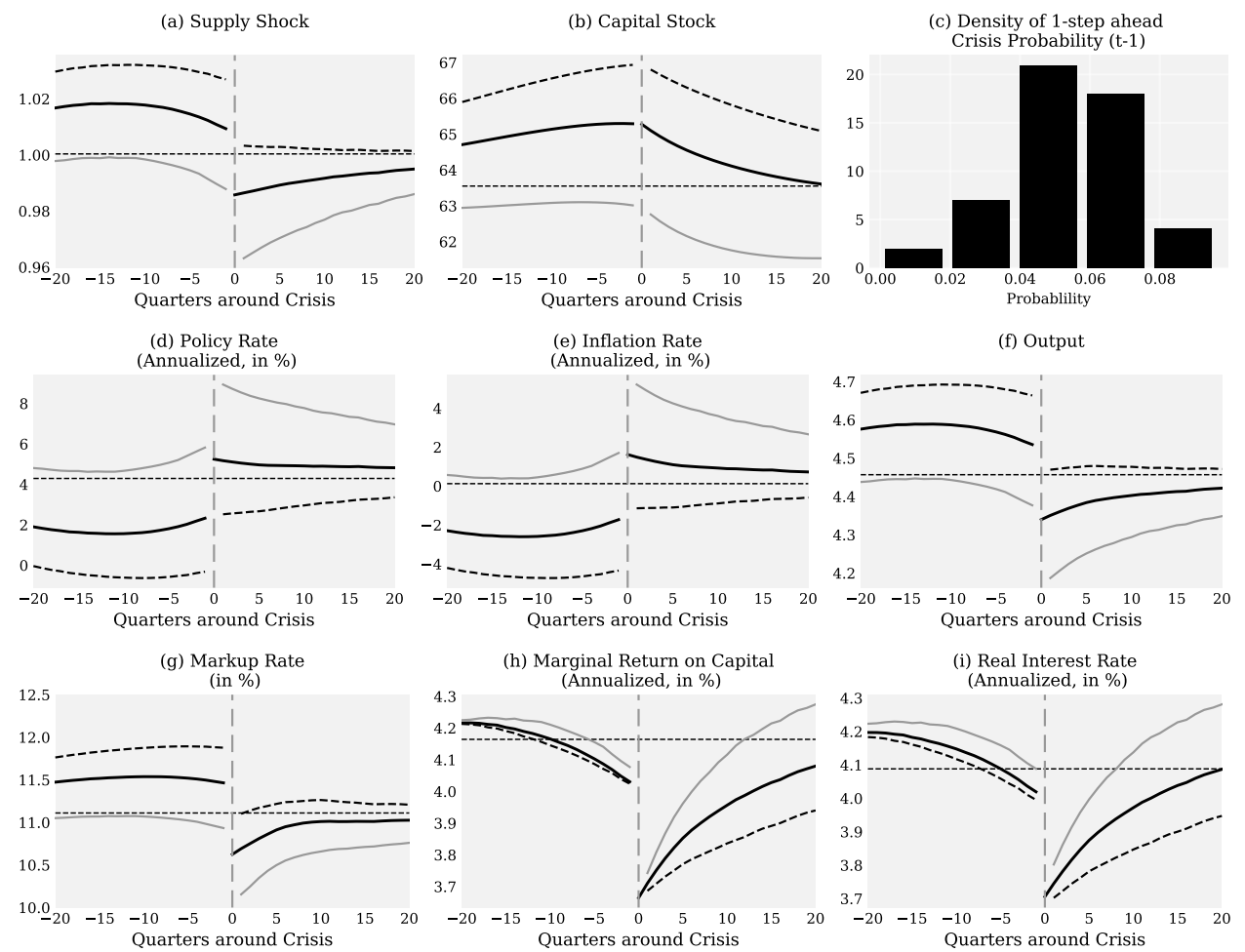

- - - Top decile Average crisis (see Figure 2)

Bottom decile

Note: Simulations for the TR93 economy. Average dynamics of the economy around the beginning of all (black $\overline{\text { line), }}$ predicted (dashed) and unpredicted (grey) crises (quarter 0), as in Figure 2. The subset of predicted (unpredicted) crises corresponds to the crises whose one-step-ahead probability in quarter - 1 is in the top (bottom) decile of its distribution (Panel (c)).

As the above discussion suggests, the average dynamics around crises reported in Figure 2 
mask the heterogeneity of financial crises in our model. To document this heterogeneity, we contrast in Figure 7.3 the average dynamics around predicted (dashed line) and unpredicted (grey line) crises with those of the average crisis (black line and Figure 2). For the purpose of this exercise, we define a crisis as "predicted" (respectively "unpredicted") if the crisis probability in the quarter that precedes it (i.e. quarter -1) is in the top (respectively bottom) decile of its distribution (Panel (c)). Our prior is that endogenous crises are more predictable than exogenous ones and, therefore, that the crisis probability can be used as a reasonable measure of endogeneity. The main findings are twofold. First, in line with our prior, unpredicted crises occur when aggregate productivity is low (Panel (a), grey line), as in the case of crisis $\mathrm{A}_{\text {exog }}$ in Figure 7.2 whereas predicted ones follow an investment boom (Panel (b), dashed line), and occur despite aggregate productivity being above average (Panel (a), dashed line), as in the case of crisis $A_{\text {endog. }}$ Second, the distribution of the one-quarter-ahead crisis probability is left-skewed (Panel (c)), with means that the bulk of crises in our model are predicted/endogenous — albeit imperfectly. These findings are consistent with recent empirical and the notion that financial crises are the byproduct of predictable boom-bust financial cycles (see Greenwood, Hanson, Schleifer, and Ahm Sørensen (2021)).

\subsection{The Role of Crisis Expectations: Savings Glut and Markup Externalities}

Figure 7.4: Savings Glut and Markup Externalities

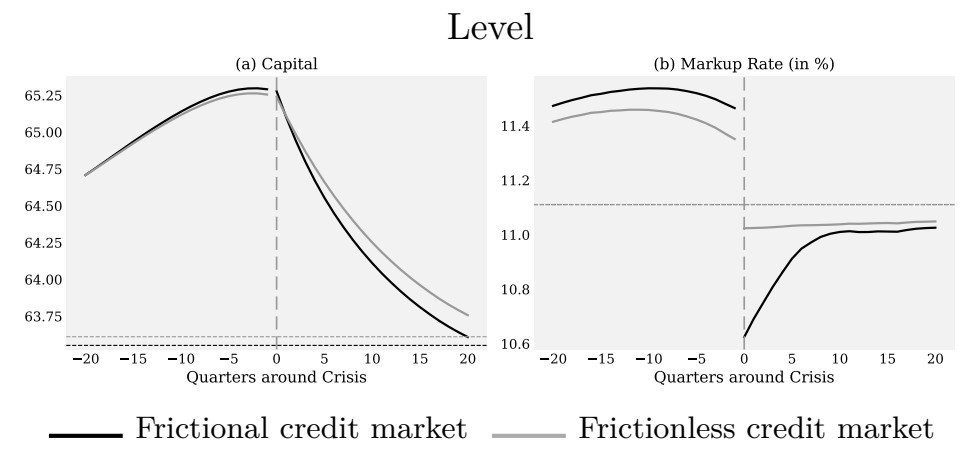

Note: The dashed lines correspond to the unconditional average in each economy.

Difference (Frictional credit market - Frictionless credit market)
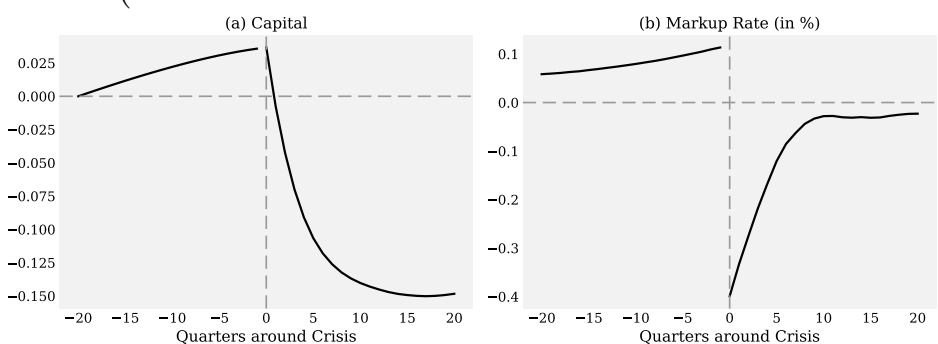

Notes: Comparison of two economies under TR93 with a frictional versus frictionless credit market. For the frictional credit market economy: same average dynamics as in Figure 2 For the frictionless credit market economy: counterfactual average dynamics, when the economy (i.e. the textbook NK economy) starts with the same capital stock in quarter $t=-20$ and is fed with the same technology shocks as the frictional credit market economy (Figure 2, Panels (a)). 
Figure 7.4 illustrates the effects of crisis expectations during investment booms. It compares the dynamics of capital and markups during booms in an economy with a frictional credit market (black line) and an economy with a frictionless credit market (grey line). Our focus is on the period from quarter -20 to quarter -1. During this period, the credit market functions perfectly and the entire capital stock is used productively and efficiently in both economies. The only difference between the two economies over this period is that, in the frictional credit market one, the household and retailers anticipate that a crisis is coming. These anticipations result in higher capital stock and markups (bottom panels), reflecting the accumulation of precautionary savings by the household (savings glut externality) and retailers' front-loading of price increases (markup externality) ahead of the crisis.

\subsection{Standard Behavior of the Model Around Steady State}

Figure 7.5: Short Run Effects: Impulse Response Functions
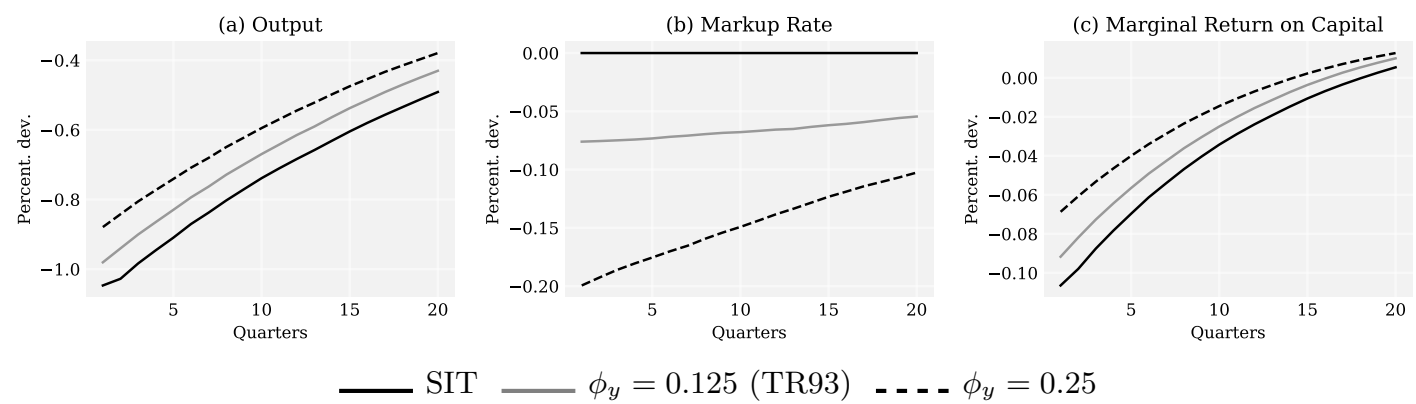

Note: Generalized impulse response functions following a negative technology under SIT, and the Taylor-type rule with $\phi_{\pi}=1.5$ and $\phi_{y}=0.125$ (TR93) or $\phi_{y}=0.25$, around the average of the ergodic distribution in the stochastic steady state.

Figure 7.5 compares the effects of a negative one-standard deviation technology shock on output, markups, and productive firms' marginal return on capital, under SIT (black line), TR93 (grey line), and a Taylor-type rule with $\phi_{y}=0.25$ (dashed line), at the stochastic steady state of the economy. Around this steady state, the economy is in normal times, the probability of a crisis is small, and the economy behaves like an economy with a frictionless credit market, which corresponds to the textbook NK economy. The differences across policy rules are well known. Following the negative shock, output falls by less while markups fall by more under Taylor-type rules than under SIT. As both effects limit the fall in productive firms' marginal return on capital, following a Taylor-type rule makes the economy more resilient than following SIT (see relation (27)).

\subsection{Model With Both Technology and Demand Shocks}

The aim of this section is to briefly describe the dynamics of our model in the presence of both technology and demand (risk-premium) shocks à la Smets and Wouters (2007) 33 For

\footnotetext{
${ }^{33}$ Such a shock creates a wedge between the interest rate controlled by the central bank and the return on assets held by the household, and has the exact opposite effects of a demand shock. A positive risk-premium (hence a negative demand) shock typically increases the required return on assets and reduces current consumption. At
} 
the purpose of comparison with our baseline case with technology shocks only, we re-calibrate parameter $\mu$ so that the economy still spends $8 \%$ of the time in a crisis in the presence of demand shocks, all the other parameters being unchanged (see Tables 1 and 7.1).

Table 7.1: Parametrization

\begin{tabular}{lcc}
\hline Parameter & Target & Value \\
\hline Aggregate risk-premium shocks & \\
$\rho_{z} \quad$ As in Smets and Wouters 2007) & 0.220 \\
$\sigma_{z}$ & 0.230 \\
\hline $\begin{array}{l}\text { Proportion of unproductive firms } \\
\mu\end{array} \quad$ The economy spends 8\% of the time in a crisis & 0.0239 \\
\hline
\end{tabular}

Figure 7.6 reports the average dynamics around crises in this economy. The comparison with Figure 2 in the main text shows that the presence of demand shocks does not affect the main dynamics and, in particular, the way macro-financial imbalances build up ahead of crises. The main difference with our baseline economy with technology shock only is to be found in the economy's short run response to shocks. Under TR93, the central bank lets output decline in the face of negative technology and demand shocks, which explains why crises coincide with recessions - the $\mathrm{Y}$-channel. At the same time, markups typically increase following negative demand shocks and decrease following negative technology shocks. These shocks therefore affect the probability of a crisis in opposite directions through the M-channel (see Figure 7.6).

Figure 7.6: Average Dynamics Around Crises With Both Technology and Demand Shocks

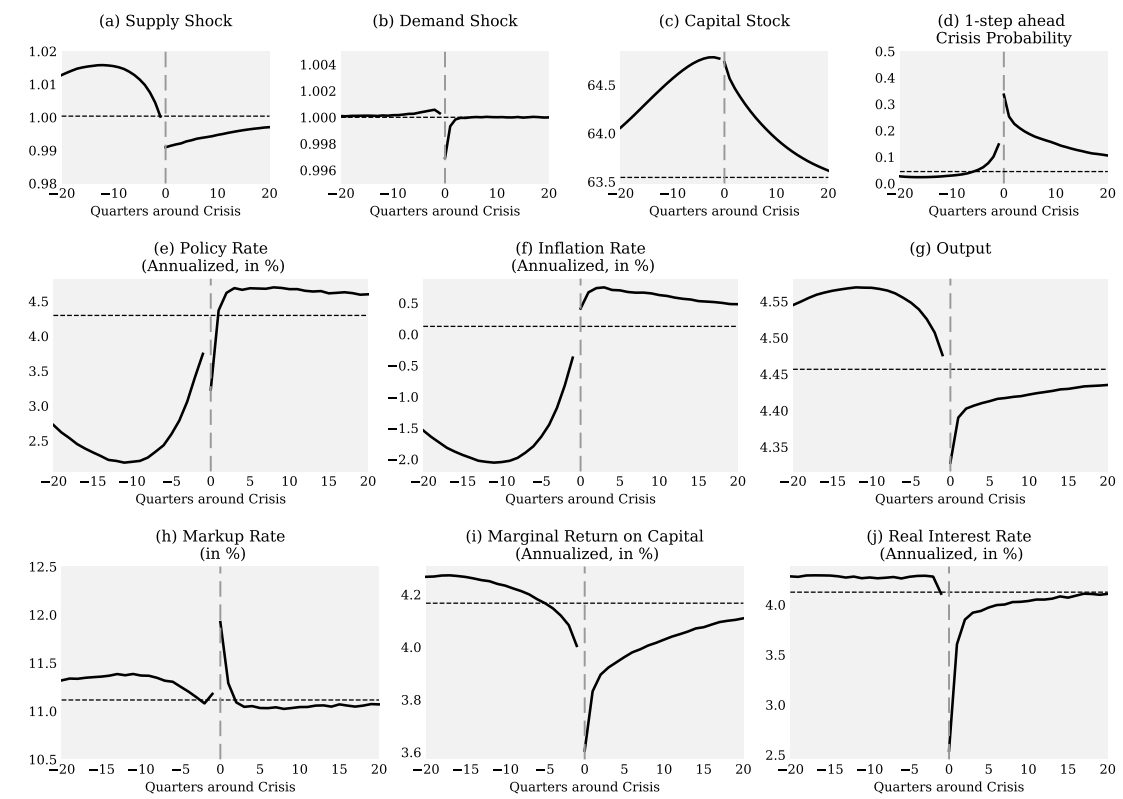

Note: Simulations for the TR93 economy, in the presence of both technology and risk-premium shocks à la Smets and Wouters (2007). Average dynamics of the economy around the beginning of a crisis (in quarter 0), as in Figure 2

the same time, it also increases firms' cost of capital and reduces the value of capital and investment. In a model with endogenous capital accumulation but without capital adjustment costs, like ours, this type of demand shock thus generates a positive correlation between consumption and investment — unlike a discount factor shock. 
Whether a crisis breaks out depends on the relative strengths of the $\mathrm{Y}-\mathrm{M}-$ and $\mathrm{K}$ - channels as well as the size of the technology versus demand shocks. To get a sense of which type of shock is most conducive to a crisis, we solve and simulate our model separately for two "counterfactual" economies that experience either technology or demand shocks — not both - and compute statistics on crises (see Table 7.2 as well as Figure 7.7). The main result is that crises are essentially due to technology shocks - either alone or in combination with demand shocks. Being relatively more persistent (see Table 1), such shocks are indeed more likely to give rise to protracted booms and capital overhang, which are pre-conditions for a crisis. Technology-driven crises also last twice as long as the demand-driven ones and, accordingly, are associated with larger losses in output.

Figure 7.7: Average Dynamics Around Crises With Either Technology or Demand Shocks
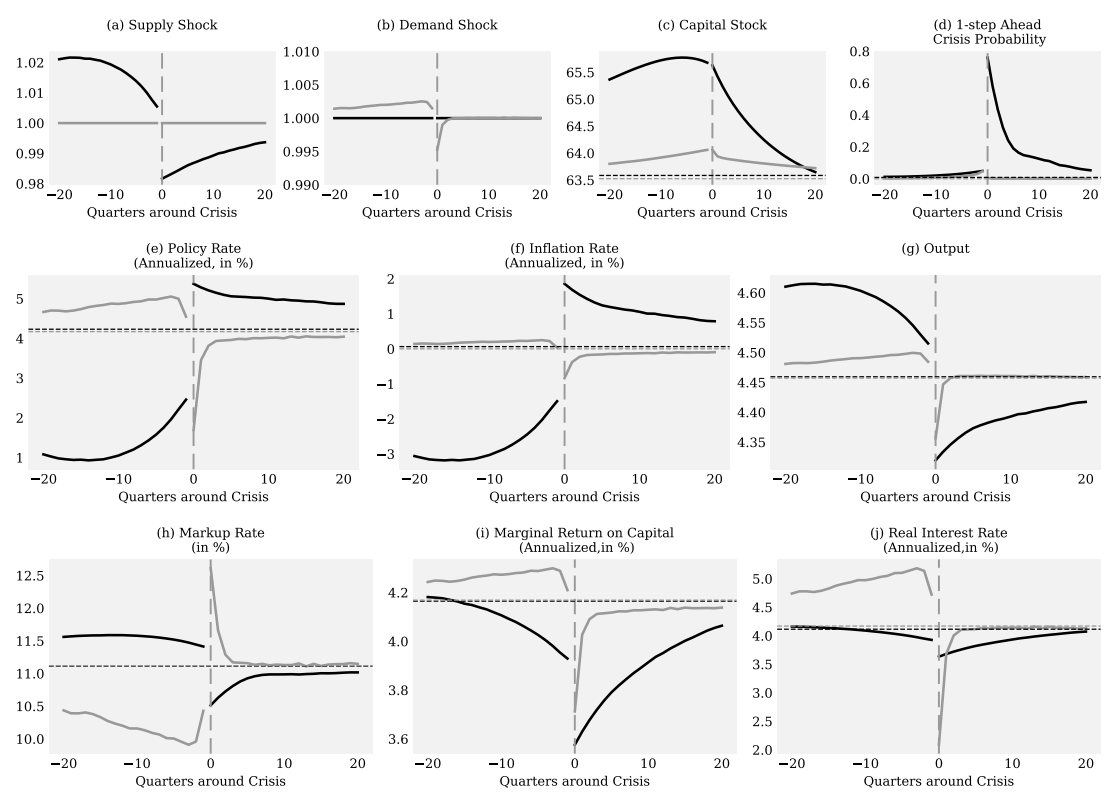

Model with TFP shocks only

Model with demand shocks only

Note: Simulations under TR93 for counterfactual economies with either technology (black line) or risk-premium shocks à la Smets and Wouters (2007) (grey line) shocks. Average dynamics of the economy around the beginning of a crisis (in quarter 0), as in Figure 2

Table 7.2: Crisis statistics and origins

\begin{tabular}{lcc}
\hline & $\begin{array}{c}\text { Crisis } \\
\text { time }(\%)\end{array}$ & $\begin{array}{c}\text { Output } \\
\text { loss }(\%)\end{array}$ \\
\hline Economy with both shocks & {$[8.00]$} & -3.20 \\
Economy with TFP shocks only & 3.42 & -4.76 \\
Economy with demand shocks only & 0.00 & -2.90 \\
\hline
\end{tabular}

Note: The first row reports statistics of the stochastic steady state ergodic distribution in the economy with both technology and demand shocks. The second and third rows report the same statistics, in counterfactual economies that experience either technology or demand shocks. In all cases, we assume that the central bank follows a TR93. "Crisis time" is the percentage of the time that the economy spends in a crisis (in \%). By construction, it is equal to $8 \%$ under TR93 (square brackets). "Output loss" is the percentage fall in output from one quarter before the crisis until the trough of the crisis (in \%). 
Table 7.3: Economic Performance and Welfare Under Alternative Policy Rules With Both Supply and Demand Shocks

\begin{tabular}{|c|c|c|c|c|c|c|c|c|}
\hline \multirow[b]{2}{*}{ Rule } & \multirow[b]{2}{*}{$\phi_{y}$} & \multirow{2}{*}{$\begin{array}{c}\text { Frictionless } \\
\mathrm{CEV}^{S I T} \\
(\%)\end{array}$} & \multicolumn{6}{|c|}{ Frictional credit market } \\
\hline & & & $\begin{array}{c}\mathrm{CEV}^{S I T} \\
(\%)\end{array}$ & $\begin{array}{c}\mathrm{CEV}^{F B} \\
(\%)\end{array}$ & $\begin{array}{c}\text { Crisis } \\
\text { time }(\%)\end{array}$ & $\begin{array}{c}\text { Length } \\
\text { (quarter) }\end{array}$ & $\begin{array}{l}\text { Output } \\
\text { loss }(\%)\end{array}$ & $\mathbb{E}\left(\pi_{t}^{2}\right)$ \\
\hline SIT & - & - & - & -0.1114 & 9.85 & 5.91 & -5.78 & 0.0000 \\
\hline \multirow{6}{*}{ 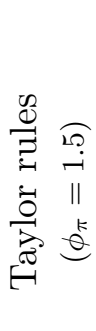 } & 0.025 & -0.0116 & -0.0992 & -0.1566 & 13.11 & 1.75 & -4.06 & 0.0006 \\
\hline & 0.050 & -0.0093 & -0.0822 & -0.1396 & 11.74 & 1.77 & -3.77 & 0.0014 \\
\hline & 0.125 & -0.0062 & -0.0407 & -0.0980 & [8.00] & 1.78 & -3.20 & 0.0065 \\
\hline & 0.250 & -0.0064 & -0.0012 & -0.0583 & 3.93 & 1.75 & -2.71 & 0.0200 \\
\hline & 0.500 & -0.0126 & 0.0270 & -0.0298 & 0.46 & 1.46 & -2.10 & 0.0524 \\
\hline & 0.750 & -0.0203 & 0.0231 & -0.0337 & 0.04 & 1.18 & -1.53 & 0.0834 \\
\hline
\end{tabular}

Note: Same statistics as in Table 2

\subsection{Equations of the Model}

The differences between our model and the textbook NK model are highlighted in red.

1. $1=\mathbb{E}_{t}\left\{\Lambda_{t, t+1}\left(1+r_{t+1}\right)\right\}$

2. $1=\mathbb{E}_{t}\left\{\Lambda_{t, t+1}\left(1+r_{t+1}^{k}\right)\right\}$

3. $\frac{W_{t}}{P_{t}}=\chi N_{t}^{\varphi} C_{t}^{\sigma}$

4. $Y_{t}=A_{t}\left(\omega_{t} K_{t}\right)^{\alpha} N_{t}^{1-\alpha}$

5. $\frac{W_{t}}{P_{t}}=\frac{\epsilon}{\epsilon-1} \frac{(1-\alpha) Y_{t}}{\mathscr{M}_{t} N_{t}}$

6. $r_{t}^{k}+\delta=\frac{\epsilon}{\epsilon-1} \frac{\alpha Y_{t}}{\mathscr{M}_{t} K_{t}}$

7. $\left(1+\pi_{t}\right) \pi_{t}=\mathbb{E}_{t}\left(\Lambda_{t, t+1} \frac{Y_{t+1}}{Y_{t}}\left(1+\pi_{t+1}\right) \pi_{t+1}\right)-\frac{\epsilon-1}{\varrho}\left(1-\frac{\epsilon}{\epsilon-1} \cdot \frac{1}{\mathscr{M}_{t}}\right)$

8. $1+i_{t}=\frac{1}{\beta}\left(1+\pi_{t}\right)^{\phi_{\pi}}\left(\frac{Y_{t}}{Y}\right)^{\phi_{y}}$

9. $Y_{t}=C_{t}+I_{t}$

10. $\Lambda_{t, t+1} \equiv \beta \frac{C_{t+1}^{-\sigma}}{C_{t}^{-\sigma}}$

11. $1+r_{t}=\frac{1+i_{t-1}}{1+\pi_{t}}$

12. $K_{t+1}=I_{t}+(1-\delta) K_{t}$

13. $\omega_{t}= \begin{cases}1 & \text { if } r_{t}^{k} \geq \frac{\mu-\delta}{1-\mu} \\ 1-\mu & \text { otherwise }\end{cases}$ 


\subsection{Global Solution Method}

The model is solved by approximating expectations using a collocation technique (see Christiano and Fisher (2000)). We first discretize the distribution of the shocks using the approach proposed by Rouwenhorst (1995). This leads to a Markov chain representation of the shock, $s_{t}$, with $s_{t} \in\left\{a_{1}, \ldots, a_{n_{a}}\right\} \times\left\{z_{1}, \ldots, z_{n_{z}}\right\}$ and transition matrix $\mathbb{T}=\left(\varpi_{i j}\right)_{i, j=1}^{n_{a} n_{z}}$ where $\varpi_{i j}=$ $\mathbb{P}\left(s_{t+1}=s_{j} \mid s_{t}=s_{i}\right)$. In what follows, we use $n_{a}=5$ and $n_{z}=5$. We look for an approximate representation of consumption, gross inflation and the gross nominal interest rate as a function of the endogenous state variables in each regime, e.g. normal times and crisis times. More specifically, we use the approximation 34

$$
G_{x}\left(K_{t} ; s\right)=\left\{\begin{array}{ll}
\sum_{j=0}^{p_{x}} \psi_{j}^{x}(n, s) T_{j}(\nu(K)) & \text { if } K \leqslant K^{\star}(s) \\
\sum_{j=0}^{p_{x}} \psi_{j}^{x}(c, s) T_{j}(\nu(K)) & \text { if } K>K^{\star}(s)
\end{array} \text { for } x=\{c, \hat{\pi}, \hat{\imath}\}\right.
$$

where $T_{j}(\cdot)$ is the Chebychev polynomial of order $j$ and $\nu(\cdot)$ maps $\left[\underline{K} ; K^{\star}(s)\right]$ in the normal regime (respectively $\left[K^{\star}(s) ; \bar{K}\right]$ in the crisis regime into) $[-1 ; 1]{ }^{35} \psi_{j}^{x}(r, s)$ denotes the coefficient of the Chebychev polynomial of order $j$ is the approximation of variable $x$ when the economy is in regime $r$ and the shocks are $s=(a, z)$. $p_{x}$ denotes the order of Chebychev polynomial we use for approximating variable $x$.

$K^{\star}(s)$ denotes the threshold in physical capital beyond which the economy falls in a crisis, defined as

$$
r_{t}^{q}+\delta=\frac{\alpha Y_{t}}{(1-\tau) \mathscr{M}_{t} K_{t}}=\frac{\mu(1-\delta)}{1-\mu}
$$

This value is unknown at the beginning of the algorithm as it depends on the decisions of the agents. We therefore also need to formulate a guess for this threshold.

\subsubsection{Algorithm}

The algorithm proceeds as follows.

1. Choose a domain $\left[K_{m}, K_{s}\right]$ of approximation for $K_{t}$ and stopping criteria $\varepsilon>0$ and $\varepsilon_{k}>0$. The domain is chosen such that $K_{m}$ and $K_{s}$ are located $30 \%$ away from the deterministic steady state of the model (located in the normal regime). We chose $\varepsilon=\varepsilon_{k}=1 \mathrm{e}^{-4}$.

2. Choose an order of approximation $p_{x}$ (we chose $p_{x}=9$ ) for $x=\{c, \hat{\pi}, \hat{\imath}\}$ ), compute the $n_{k}$ roots of the Chebychev polynomial of order $n_{k}>p$ as

$$
\zeta_{\ell}=\cos \left(\frac{(2 \ell-1) \hat{\pi}}{2 n_{k}}\right) \text { for } \ell=1, \ldots, n_{k}
$$

and formulate an initial gues $\AA^{36}$ for $\psi_{j}^{x}(n, s)$ for $x=\{c, \hat{\pi}, \hat{\imath}\}$ and $i=1, \ldots, n_{a} \times n_{z}$. Formulate a guess for the threshold $K^{\star}(s)$.

\footnotetext{
${ }^{34}$ Throughout this section, we denote $\hat{\pi}=1+\pi$ and $\hat{\imath}=1+i$.

${ }^{35}$ More precisely, $\nu(K)$ takes the form $\nu(K)=2 \frac{K-\underline{K}}{K^{\star}(s)-\underline{K}}-1$ in the normal regime and $\nu(K)=2 \frac{K-K^{\star}(a, z)}{\bar{K}-K^{\star}(s)}-1$ in the crisis regime.

${ }^{36}$ The initial guess is obtained from a first order approximation of the model around the deterministic steady state.
} 
3. Compute $K_{\ell}, \ell=1, \ldots, 2 n_{k}$ as

$$
K_{\ell}= \begin{cases}\left(\zeta_{\ell}+1\right) \frac{K^{\star}(s)-K_{m}}{2}+K_{m} & \text { for } K \leqslant K^{\star}(s) \\ \left(\zeta_{\ell}+1\right) \frac{K_{s}-K^{\star}(s)}{2}+K^{\star}(s) & \text { for } K>K^{\star}(s)\end{cases}
$$

for $\ell=1, \ldots, 2 n_{k}$.

4. Using a candidate solution $\Psi=\left\{\psi_{j}^{x}\left(r, s_{i}\right) ; x=\{c, \hat{\pi}, \hat{\imath}\}, r=\{n, c\}, i=0 \ldots p_{x}\right\}$, compute approximate solutions $G_{c}\left(K ; s_{i}\right), G_{\hat{\pi}}\left(K ; s_{i}\right)$ and $G_{\hat{\imath}}\left(K ; s_{i}\right)$ for each level of $K_{\ell}$, $\ell=1, \ldots, 2 n_{k}$ and each possible realization of the shock vector $s_{i}, i=1, \ldots, n_{a} \times n_{z}$ and the over quantities of the model using the definition of the general equilibrium of the economy (see below). In particular, compute the next period capital $K_{\ell, i}^{\prime}=G_{K}\left(K_{\ell} ; z_{i}\right)$ for each $\ell=1, \ldots, 2 n_{k}$ and $i=1 \ldots n_{a} \times n_{z}$.

5. Using the next period capital and the candidate approximation, solve the general equilibrium to obtain next period quantities and prices entering the expectations in the household's Euler equations and in the price setting equation. Compute expectations

$$
\begin{aligned}
& \widetilde{\mathscr{E}}_{c, t}=\beta \sum_{s=1}^{n_{z}} \varpi_{i, s}\left[u^{\prime}\left(G_{c}\left(K_{\ell, i}^{\prime}, z_{s}^{\prime}\right)\right)\left(1+r^{k^{\prime}}\left(K_{\ell, i}^{\prime}, z_{s}^{\prime}\right)\right)\right] \\
& \widetilde{\mathscr{E}}_{\hat{\imath}, t}=\beta \sum_{s=1}^{n_{z}} \varpi_{i, s}\left[\frac{u^{\prime}\left(G_{c}\left(K_{\ell, i}^{\prime}, z_{s}^{\prime}\right)\right)}{G_{\hat{\pi}}\left(K_{\ell, i}^{\prime}, z_{s}^{\prime}\right)}\right] \\
& \widetilde{\mathscr{E}}_{\hat{\pi}, t}=\beta \sum_{s=1}^{n_{z}} \varpi_{i, s}\left[u^{\prime}\left(G_{c}\left(K_{\ell, i}^{\prime}, z_{s}^{\prime}\right)\right) G_{Y}\left(K_{\ell, i}^{\prime}, z_{s}^{\prime}\right) G_{\hat{\pi}}\left(K_{\ell, i}^{\prime}, z_{s}^{\prime}\right)\left(G_{\hat{\pi}}\left(K_{\ell, i}^{\prime}, z_{s}^{\prime}\right)-1\right)\right]
\end{aligned}
$$

6. Use expectations to compute $c, \hat{\pi}$ and $\hat{\imath}$

$$
\begin{aligned}
& \widetilde{c}_{t}=u^{\prime-1}\left(\widetilde{\mathscr{E}}_{c, t}\right) \\
& \widetilde{\hat{\imath}}_{t}=z \frac{u^{\prime}\left(G_{c}\left(K_{\ell}, z_{i}\right)\right)}{\widetilde{\mathscr{E}}_{\hat{\imath}, t}} \\
& \widetilde{\hat{\pi}}_{t}=\frac{\sqrt{1+4 \Delta_{t}}-1}{2}
\end{aligned}
$$

where

$$
\Delta_{t} \equiv \frac{\widetilde{\mathscr{E}}_{\tilde{\pi}, t}}{G_{c}\left(K_{\ell}, z_{i}\right)^{-\sigma} G_{y}\left(K_{\ell}, z_{i}\right)}-\frac{\epsilon-1}{\varrho}\left(1-\frac{\epsilon}{\epsilon-1} \frac{1}{G_{\mathscr{M}}\left(K_{\ell}, z_{i}\right)}\right)
$$

7. Project $\widetilde{c}_{t}, \widetilde{\hat{\imath}}_{t}, \widetilde{\hat{\pi}}_{t}$ on the Chebychev polynomial $T_{j}(\cdot)$ to obtain a new candidate vector of approximation coefficients, $\widetilde{\Psi}$. If $\|\widetilde{\Psi}-\Psi\|<\varepsilon \xi$ then a solution was found and go to step 8 , otherwise update the candidate solution as

$$
\xi \widetilde{\Psi}+(1-\xi) \Psi
$$

where $\xi \in(0,1]$ can be interpreted as a learning rate, and go back to step 3 . 
8. Upon convergence of $\Psi$, compute $\widetilde{K}^{\star}(s)$ that solves (32). If $\left\|\widetilde{K}^{\star}(s)-K^{\star}(s)\right\|<\varepsilon_{k} \xi_{k}$ then a solution was found, otherwise update the threshold as

$$
\xi_{k} \widetilde{K}^{\star}(s)+\left(1-\xi_{k}\right) K^{\star}(s)
$$

where $\xi_{k} \in(0,1]$ can be interpreted as a learning rate on the threshold, and go back to step 3.

\subsubsection{Computing the General Equilibrium}

In this section, we explain how the general equilibrium is solved. Given a candidate solution $\Psi$, we present the solution for a given level of the capital stock $K$, a particular realization of the shocks $(a, z)$. For convenience, and to save on notation, we drop the time index.

For a given guess on the threshold, $K^{\star}(a, z)$, test the position of $K$.

If $K \leqslant K^{\star}(a, z)$, the economy is in normal times. Using the approximation guess, we get immediately

$$
C=G_{c}^{n}(K, s), \hat{\pi}=G_{\hat{\pi}}^{n}(K, s), \hat{\imath}=G_{\hat{\imath}}^{n}(K, s)
$$

and $\bar{q}=1$. If $K>K^{\star}(a, z)$, the economy is in crisis times. Using the approximation guess, we get immediately

$$
C=G_{c}^{c}(K, s), \hat{\pi}=G_{\hat{\pi}}^{c}(K, s), \hat{\imath}=G_{\hat{\imath}}^{c}(K, s)
$$

and $\bar{q}=1-\mu$. Using the Taylor rule, we obtain aggregate output as

$$
Y=\bar{Y}\left(\frac{\beta \hat{\imath}}{\hat{\pi}^{\phi_{\pi}}}\right)^{\frac{1}{\phi_{y}}}
$$

and, from the production function, the level of hours required to produce it as

$$
N=\left(\frac{Y}{a\left(\bar{q} K^{\alpha}\right)}\right)^{\frac{1}{1-\alpha}}
$$

which leads to a markup rate of

$$
\mathscr{M}=\frac{1-\alpha}{\chi(1-\tau)} \frac{Y}{N^{1+\varphi}} C^{-\sigma}
$$

and a rate of return on capital of

$$
r^{q}=\frac{\alpha}{1-\tau} \frac{Y}{\mathscr{M} K}-\delta
$$

The investment level obtains directly from the resource constraint as

$$
x=Y-c
$$

implying a value for the next capital stock of

$$
K^{\prime}=x+(1-\delta) K
$$




\subsubsection{Accuracy}

In order to asses the accuracy of the approach, we compute the relative errors an agent would makes if they used the approximate solution. In particular, we compute the quantities

$$
\begin{aligned}
& \mathscr{R}_{c}(K, z)=\frac{C_{t}-\left(\beta \mathbb{E}_{t}\left[C_{t+1}^{-\sigma}\left(1+r_{t+1}^{q}\right)\right]\right)^{-\frac{1}{\sigma}}}{C_{t}} \\
& \mathscr{R}_{\hat{\imath}}(K, z)=\frac{C_{t}-\left(\beta \frac{\hat{\imath} t}{z_{t}} \mathbb{E}_{t}\left[\frac{C_{t+1}^{-\sigma}}{\hat{\pi}_{t+1}}\right]\right)^{-1 / \sigma}}{C_{t}} \\
& \mathscr{R}_{\hat{\pi}}(K, z)=\hat{\pi}_{t}\left(\hat{\pi}_{t}-1\right)-\beta \mathbb{E}_{t}\left[\left(\frac{C_{t+1}}{C_{t}}\right)^{-\sigma} \frac{Y_{t+1}}{Y_{t}} \hat{\pi}_{t+1}\left(\hat{\pi}_{t+1}-1\right)\right)+\frac{\epsilon-1}{\varrho}\left(1-\frac{\epsilon}{\epsilon-1} \cdot \frac{1}{\mathscr{M}_{t}}\right)
\end{aligned}
$$

where $\mathscr{R}_{c}(K, z)$ and $\mathscr{R}_{\hat{\imath}}(K, z)$ denote the relative error in terms of consumption an agent would make by using the approximate expectation rather than the "true" rational expectation in the household's Euler equation. $\mathscr{R}_{\hat{\pi}}(K, z)$ corresponds to the error on inflation. All these errors are evaluated for values for the capital stock that lie outside of the grid that was used to compute the solution. We used 1,000 values uniformly distributed between $K_{m}$ and $K_{s}$. Table 7.4 reports

\begin{tabular}{|c|c|c|c|c|}
\hline & \multirow[b]{2}{*}{$\phi_{y}$} & \multicolumn{3}{|c|}{ Average absolute errors } \\
\hline & & $E^{c}$ & $E^{\hat{\imath}}$ & $E^{\hat{\pi}}$ \\
\hline SIT & - & -5.6088 & - & - \\
\hline \multirow{6}{*}{ 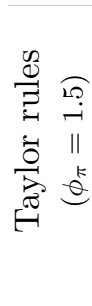 } & 0.025 & -5.5378 & -5.5277 & -5.2331 \\
\hline & 0.050 & -5.4967 & -5.5603 & -5.1380 \\
\hline & 0.125 & -5.3805 & -5.1154 & -4.9550 \\
\hline & 0.250 & -5.2889 & -4.9216 & -4.8640 \\
\hline & 0.500 & -5.5570 & -4.9748 & -5.0796 \\
\hline & 0.750 & -5.5235 & -4.8875 & -5.0160 \\
\hline
\end{tabular}
the average of absolute errors, $E^{x}=\log _{10}\left(\frac{1}{n_{k} \times n_{a} \times n_{z}} \sum\left|\mathscr{R}_{x}(K, s)\right|\right)$, for $x \in\{c, \hat{\imath}, \hat{\pi}\}$.

Table 7.4: Accuracy Measures

Note: $E^{x}=\log _{10}\left(\frac{1}{n_{k} \times n_{a} \times n_{z}} \sum\left|\mathscr{R}_{x}(K, s)\right|\right)$ is the average of the absolute difference, in terms of the level of consumption, that is obtained if agents use the approximated expectation of variable $x$ instead of its "true" rational expectation, for $x \in\{c, \hat{\imath}, \hat{\pi}\}$.

Concretely, $E^{c}=10^{-5.6088}$ (first row, second column) means that the average error an agent makes in terms of consumption by using the approximated decision rule - rather than the true one- under SIT amounts to $\$ 2.46$ per $\$ 1,000,000$ spent. The largest approximation errors in the decision rules are made at the threshold values for the capital stock where the economy shifts from normal to crisis times. But even there, the maximal errors are relatively small, in the order of $\$ 150$ per $\$ 1000,000$ of consumption, and rare. By the usual standards, our approximation of agents' decision rules is therefore very accurate. 